\title{
Conditional gene expression in invertebrate animal models
}

Brecht Driesschaert ${ }^{1, a}$, Lucas Mergan ${ }^{1, a}$, Liesbet Temmerman*,a

Brecht.Driesschaert@kuleuven.be, Lucas.Mergan@kuleuven.be, Liesbet.Temmerman@kuleuven.be

${ }^{a}$ Animal Physiology and Neurobiology, Department of Biology, University of Leuven (KU Leuven), Naamsestraat 59 - box 2465, B-3000 Leuven, Belgium

${ }^{1}$ equally contributing authors

*corresponding author 


\section{Abstract}

2 A mechanistic understanding of biology requires appreciating spatiotemporal aspects of gene expression

3 and its functional implications. Conditional expression allows for (ir)reversible switching of genes on or

4 off, with the potential of spatial and/or temporal control. This provides a valuable complement to the

5 more often used constitutive gene (in)activation through mutagenesis, providing tools to answer a wider

6 array of research questions across biological disciplines. Spatial and/or temporal control are granted

7 primarily by (combinations of) specific promoters, temperature regimens, compound addition, or

8 illumination. The use of such genetic tool kits is particularly widespread in invertebrate animal

9 models because they can be applied to study biological processes in short time frames and on large

10 scales, using organisms amenable to easy genetic manipulation. Recent years witnessed an exciting

11 expansion and optimization of such tools, of which we provide a comprehensive overview and

12 discussion regarding their use in invertebrates. The mechanism, applicability, benefits, and drawbacks of

13 each of the systems, as well as further developments to be expected in the foreseeable future, are

14 highlighted.

15 Keywords

16 Conditional gene expression; Spatiotemporal control; Invertebrate; Model organism; Drosophila

17 melanogaster; Caenorhabditis elegans 


\section{Introduction}

The field of genetics owes a great debt to invertebrate animal models, which have repeatedly proven to be very powerful models to study biological processes. Their generally short life cycles and large numbers of offspring, combined with relatively easy genetic manipulation, allow for the generation and screening of mutants on a large scale and within modest time frames. Because many genes are well conserved between invertebrates and humans, their study has also vastly expanded our knowledge of human biology. Because of their extensive use in the field of functional genetics, it is not surprising that the tools available to study genetic regulation of biological processes in such model organisms continue to diversify.

For several years now, it has become relatively easy to constitutively (in)activate genes using (targeted) mutagenesis, and publicly available collections of mutated model organisms keep expanding as valuable resources for functional research. However, not all research questions can be approached by this rationale as mutating some genes can lead to unwanted side effects. Typical examples include mutations leading to infertility or lethality, which tend to complicate functional genetic experiments. In several cases, it can therefore be useful to gain temporal control over gene expression, for example, when aiming to uncouple the role(s) of a gene in an adult organism from its role(s) during development. While several tools for conditional gene expression are conceptually shared with those used in vertebrate model organisms (e.g., reviewed in the studies by Lewandoski, 2001; Maltzman and Turka, 2007; and Kallunki et al., 2019), the appeal of fast and easy genetics of invertebrate animal models has led to tool kit specification and expansion for these organisms.

With this review, we aim to present a comprehensive overview of the current methods for temporal control of transcription that are available for invertebrate animal models, including their advantages and disadvantages, with a major focus on Drosophila melanogaster and Caenorhabditis elegans, as most tools were developed in these model organisms. We here consider both unidirectional and bidirectional control, meaning either irreversibly or reversibly switching the expression of a target gene on or off, via heat, compounds, or light, as well as propose potential future developments relevant to the field.

\section{Heat shock promoters enable temperature-based control over gene expression}

The oldest and perhaps most straightforward system for inducible gene expression is based on the use of endogenous heat shock responsive promoters to drive transgene expression. At elevated temperatures, constitutively expressed but inactive heat shock factors (HSFs) trimerise, allowing them 
to bind specific heat shock promoters (hsp) that activate the transcription of heat shock genes (Fig. 1).

49 The canonical heat shock response is present across organisms, first characterized by Ritossa (1962) in D. melanogaster. In 1983, an hsp-70p::hsp-70::lacZ fusion was shown to be expressed in extracts from

51 heat-shocked but not from non-heat-shocked $D$. melanogaster through a $\beta$-galactosidase activity assay

52 (Lis et al., 1983), and in 1992, the same was seen in C. elegans using an hsp-16p::hsp-16::/acZ hybrid

53 (Stringham et al., 1992), validating that these systems can be used for rapid expression of a protein of

54 interest. Since then, the value of the endogenous heat shock response for conditional transgene expression has been demonstrated in many other invertebrate representatives, including experiments in sea urchin embryos (McMahon et al., 1984), the sea squirt Ciona intestinalis (Kawaguchi et al., 2015), and cell lines of the beetle Tribolium castaneum (Silver et al., 2015). The system is also promising for use in many nonmodel invertebrates, primarily insects (Chen et al., 2020).

When relying on an endogenous heat shock promoter, transgene expression is typically activated in diverse tissues simultaneously. In C. elegans (Stringham and Candido, 1993) and D. melanogaster (Halfon et al., 1997), it is possible to add a spatial element of control by using a laser to restrict the area of heat shock induction, even to individual cells. An additional possibility in the nematode involves working in a $h s f-1$ knockout background and reintroducing $h s f-1$ cell-specifically (Bacaj and Shaham, 2007). Many other systems of conditional expression still rely on heat shock promoters for temporal control, as will be discussed in the following sections.

There are several significant disadvantages to using heat shock promoters for conditional gene expression. First of all, a major drawback is the necessity of exposing experimental animals to high temperatures. This can lead to unwanted effects when examining phenomena influenced by temperature, such as life span, reproduction, and behavior (Lithgow et al., 1994; Hercus et al., 2003; Hill et al., 2014; Nikitina et al., 2014). Second, the response is transient, meaning transgene expression will disappear again after some time (e.g., Didomenico et al., 1982; Fortin et al., 2014), which is problematic when sustained expression within a specific time frame is desired. Third, leaky expression has been observed even at lower temperatures, when no expression is wanted (Steller and Pirrotta, 1985). Finally, unless using lasers to induce the heat shock or having to work with specific genetic backgrounds, which may bring along difficulties of their own, there is no spatial control. Therefore, current tools for conditional expression that rely on heat shock promoters tend to use these in combination with other systems, or have been completely replaced by other systems, as described in the following sections. 
3. Site-directed recombination unidirectionally switches expression on or off using heat, compounds, or light

Two inducible expression systems that are widely adopted are based on site-specific recombinases. These recombinase enzymes can bind and bring together two DNA recognition sites and then cleave, exchange, and rejoin the DNA strands (Fig. 2). This leads to the removal or reversal of the DNA sequence in between these two sites. The Cre-LoxP system was adapted from P1 bacteriophages by Sauer (1987) and Sauer and Henderson (1988) for use in Saccharomyces cerevisiae and mammalian cells, respectively, whereas the Flp-FRT system was derived from yeast by Golic and Lindquist (1989), who applied it in $D$. melanogaster. In both cases, a site-specific recombinase (Cre, encoded by a locus originally named Causes recombination [Sternberg, 1981], or Flp, short for flippase [Broach and Hicks, 1980 ]) is able to excise or invert a sequence flanked by a pair of 34-bp recognition sites (IoxP, locus of crossover in P1 [Sternberg, 1981], or FRT, flippase recognition target [McLeod et al., 1986]). Recombinases can also be used to insert DNA sequences into genomic DNA containing the recognition sequence, but this will not be discussed here because it is of little relevance to conditional gene expression. When the recognition sites occur in the same orientation, the sequence contained between them is excised, whereas opposite orientations result in an inversion. The former is often used for gene inactivation (Golic and Lindquist, 1989; Hoier et al., 2000; Vázquez-manrique et al., 2010) (Fig. 2A), while the latter allows for inactivation by inverting a sequence to its correct orientation (Vázquez-manrique et al., 2010; Flavell et al., 2013) (Fig. 2B). Other methods of gene activation are the lox-stop-lox or Flp-out systems, which are based on excision of genetically introduced stop cassettes, containing a stop codon flanked by loxP or FRT sites upstream of a sequence of interest. Upon activation of the recombinase, the stop cassette is excised, and the sequence can be transcribed (Struhl and Basler, 1993; Davis et al., 2008; Voutev and Hubbard, 2008) (Fig. 2C). All this can be carried out spatially (tissuespecific promoter) (Golic and Lindquist, 1989; Hoier et al., 2000), temporally (heat shock promoter) (Newsome et al., 2000; Voutev and Hubbard, 2008), or by both means (Struhl and Basler, 1993; Davis et al., 2008; Voutev and Hubbard, 2008). Many variants have been designed for various end goals, as described in more detail in the following paragraphs. Cre-LoxP was first introduced in D. melanogaster in 1996 to introduce transgenes at specific allelic sites

106 (Siegal and Hartl, 1996) and in C. elegans in 2000 to inactivate a gene postembryonically (Hoier et al., 107 2000). Flp-FRT was used in C. elegans for the first time in 2008 for spatial and temporal gene activation 108 (Davis et al., 2008; Voutev and Hubbard, 2008). These recombinase systems have been applied in a 
number of insect species, such as the pest Anastrepha suspensa (Schetelig and Handler, 2013), the disease vector Aedes aegypti (Morris et al., 1991), and the economically important lepidopteran Bombyx mori (Long et al., 2012), with the latter also having seen the use of stop cassettes (Duan et al., 2013). Besides Cre-LoxP and Flp-FRT, Hubbard (2014) gives a comprehensive overview of the use of Cre-LoxP and Flp-FRT in C. elegans up until 2014, while Germani et al. (2018) provide a similar summary for Flp-FRT applications in D. melanogaster up until 2018. We here provide an updated summary of these tools' main applications in these organisms, specifically in the context of conditional expression.

For D. melanogaster, Flp-FRT seems more successful than Cre-LoxP as toxic effects have been reported when expressing the Cre recombinase in this fruit fly (Heidmann and Lehner, 2001), including in studies directly comparing both systems (Nern et al., 2011; Frickenhaus et al., 2015). FRT sites have been integrated into all major chromosome arms, allowing for trans-chromosomal recombination resulting in mosaic animals. This can be used to investigate recessive mutations that are lethal when homozygous in fly embryos or larvae (Xu and Rubin, 1993) or to determine whether intervening with gene expression in one cell affects the biology of the neighboring cells (Heitzler and Simpson, 1991) (Fig. 2D). Further developments of Flp-FRT for conditional gene expression in D. melanogaster include Mutant Analysis by Rescue Gene Excision, in which a cassette containing a rescuing gene for a homozygous mutation can be excised, leading to conditional loss of expression (Zhou et al., 2016); FlpStop, wherein a cassette consisting of disruptive elements can be inverted irreversibly to halt gene expression (Fisher et al., 2017); and Flip-flop, which functions similar to FlpStop but expresses EGFP when gene expression is on and mCherry when it is off (Manivannan et al., 2019). The latter two depend on a flip excision (FLEx) switch for their irreversibility, using two incompatible pairs of $F R T$ sites (Fig. 2E). Another interesting adaptation is the compound-regulated Flp-DD, which contains a destabilizing domain (DD) that results in Flp degradation, until addition of the stabilizing agent trimethoprim (Fig. 2F). Thus, recombinase activity is uncoupled from heat shock, instead of being regulated by feeding with a small molecule (Sethi and Wang, 2017). Although Cre recombinase is less popular in D. melanogaster owing to its toxicity, this has been circumvented by creating a nontoxic fusion of Cre to the ligand-binding domain (BD) of the human estrogen receptor. This Cre-estrogen BD (Cre-EBD) fusion allows for recombination upon addition of estrogen (Fig. 2G); however, the reaction may not occur in all cells where Cre-EBD is expressed (Heidmann and Lehner, 2001), and Flp-FRT has remained the recombinase of choice in D. melanogaster, as evidenced by the number of Cre/LoxP and Flp/FRT strains available at the Bloomington Drosophila Stock Center ( \pm 20 vs \pm 450 ). Nevertheless, some researchers have managed to apply Cre successfully and inventively in the fruit fly: for example, a photoactivatable split-Cre system that allows dimerization 
141 of two Cre halves upon blue light illumination, consequently enabling recombination and gene

142 (in)activation (Boulina et al., 2013) (Fig. 2H). An important distinction with the other recombination-

143 based techniques is that this makes it possible to activate Cre enzyme activity, rather than the

144 transcription of the Cre gene, which should benefit temporal dynamics. Finally, it should be noted that

$145 \mathrm{Flp} / F R T$ and Cre/LoxP are not the only recombinase systems for conditional expression in the fruit fly.

146 For example, PhiC31 is a phage-derived recombinase that acts upon attB and attP sites, to invert, excise,

147 or insert a sequence unidirectionally owing to its asymmetric landing sites, and can be applied in

148 D. melanogaster (Groth, 2004; Knapp et al., 2015; Luo et al., 2019). Moreover, its use has been

149 expanded to other insects, which are listed in Table 1 (Nimmo et al., 2006; Labbé et al., 2010; Meredith

150 et al., 2011; Yonemura et al., 2013; Haghighat-Khah et al., 2015). Other recombinases from different

151 yeast species that also show strong activity and no toxicity in D. melanogaster are KD, $R, B 2$, and B3

152 recombinases. These can be used in combination with each other, or with Flp, as they do not recognize

153 each other's target sequences (excluding the combination R and B2) (Nern et al., 2011).

154 In C. elegans, both Cre-LoxP and Flp-FRT have been used regularly. In cases where desired cell-specific

155 promoters are unavailable, using different tissue-specific promoters for the recombinase and target

156 genes permits to further restrict target gene expression to the intersecting cells of both promoters

157 (Macosko et al., 2009). In this context, Kage-Nakadai et al. (2014) created a source of tissue-specific and

158 heat shock-driven Cre recombinase strains with multicopy expression, which can be crossed into strains

159 carrying loxP-flanked sequences of interest. While many experiments used to rely on such multicopy

160 transgenic strains (either carrying the recombinase extrachromosomally or relying on DNA constructs

161 that were integrated randomly into the genomic DNA), targeted genome editing technologies greatly

162 facilitated single-copy expression of recombinase and/or target transgenes from the genome (Lo et al.,

163 2013; Chen et al., 2018). Consequently, Muñoz-jiménez et al. (2017) generated a set of single-copy

164 transgenic $C$. elegans strains expressing Flp recombinase reliably upon heat induction or in specific

165 tissue types. The newest adaptation of the Cre system in C. elegans is Laser Targeted Activation of Cre,

166 based on a photoactivatable version of Cre, which uses infrared light instead of heat to achieve

167 activation. It does so by cell-specifically incorporating a noncanonical photocaged amino acid into the

168 active site of Cre, allowing for both spatial and temporal control of gene expression (Davis et al., 2020)

169 (Fig. 2I). As mentioned as an advantage of photoactivatable Cre in D. melanogaster, this also does not

170 depend on temporal Cre transcription, but rather on temporal control over the functional reconstitution

171 of available Cre protein. 
172 Despite their many advantages, site-directed recombinases are genetic tools that entail their own risks

173 and limitations. One well-known risk would be the possibility of unpredictable side effects of the

174 recombinase enzyme, as is clearly evident for Cre in D. melanogaster (Heidmann and Lehner, 2001; Nern

175 et al., 2011; Frickenhaus et al., 2015), and it is also a major issue in mammals, where it is very popular

176 nonetheless (Schmidt-Supprian and Rajewsky, 2007). Moreover, most systems still rely on temporal

177 control via heat shock promoters, whose limitations have been listed previously. Spatial control on the

178 other hand relies on the availability of appropriate tissue-specific promoters, and it is important to verify

179 their assumed specificity under the appropriate experimental conditions, which may differ from those of

180 reported expression patterns. In addition, it is essential to always confirm that the intended inversion or

181 excision event has actually taken place, and the inclusion of a reporter is thus recommended. On top of

182 this, working with inversions is a little more challenging because DNA fragments flanked by inverted

183 recognition sites may continue to randomly reverse back and forth while the recombinase is active. A

184 technique that prevents this is the FLEx switch (Schnütgen et al., 2003), applying incompatible pairs of

185 loxP or FRT sites, resulting in stable, single inversion. In $D$. melanogaster, this has currently only been

186 used in the FlpStop and Flip-Flop systems, and in C. elegans, the method is yet to be successfully

187 introduced. Unlike inversions, excisions tend to be practically irreversible (thanks to the loss of the

188 circular reaction product), meaning that excisable stop cassettes do not suffer from this issue. Although

189 there seems to be a general consensus that read-through of stop cassettes leading to low-level target

190 expression in the absence of the matching recombinase is not uncommon, there are few published data

191 supporting this (in mice, very low and rare read-through has been reported [Kuhlman and Huang, 2008],

192 whereas other articles refer to unpublished observations [Kaczmarczyk, 2001]). Research into the

193 frequency and level of this leaky expression (in invertebrates) would be of great interest. Inversely,

194 incomplete removal of the stop cassette leading to variable levels of expression has also been

195 demonstrated in mice (Bapst et al., 2020), and the incidence of this phenomenon in invertebrates would

196 also be useful to quantify. Although the irreversibility of the ultimate result of recombinase systems can

197 be advantageous in some cases, it can also be a major disadvantage in and of itself as it is a one-way

198 street: once Cre or Flp has been induced and executed the recombination reaction, target expression is

199 permanently turned on or off. Systems allowing for bidirectional control offer a greater range of

200 experimental uses - the systems described in the following sections (in principle) permit such

201 applications.

202 4. Tetracycline-controlled transcriptional activation depends on small molecules for temporal control 
Many transcription factors rely on small molecules as inducers or activators, which provides a window of opportunity to develop conditional gene expression systems with improved temporal control: as opposed to use of heat shock and/or spatio-specific promoters, use of compounds also permits deliberately stopping an effect after it has been induced. One such group of genetic tools is based on a transcriptional activator that is regulated by tetracycline (Tet) and its derivatives (such as doxycycline [Dox]). The Tet-Off system was adapted from Escherichia coli by Gossen and Bujard (1992) for application in mammalian cells and shortly after expanded to the Tet-On system by Gossen et al. (1995). Both use a chimeric protein consisting of the Tet repressor (TetR) and the transactivator virus protein 16

211 (VP16), which together function as a transcriptional activator (Fig. 3). In the Tet-Off system, this chimeric 212 protein is called the tetracycline transactivator (tTA). It can be expressed in a tissue of choice, where it 213 can then bind tet operator (tetO) sequences in the DNA to activate transcription of a downstream 214 cytomegalovirus (CMV) minimal promoter. A combination of one or several operator sequences and the 215 minimal promotor is called a tetracycline response element (TRE), and this can be placed upstream of a 216 sequence of interest by standard genetic manipulation. When Tet or Dox is added, they will bind tTA, 217 causing it to dissociate from the TRE, thus halting expression (Fig. 3A). The Tet-On system instead uses a 218 slightly different chimeric protein, the reverse tetracycline transactivator (rtTA), which can only bind TRE 219 and activate transcription when in the presence of Tet or Dox (Fig. 3B). By restricting the expression of 220 tTA or rtTA to a tissue or cell type of interest and adding Tet or Dox at a specific time point, these 221 systems allow for both spatial and temporal control of gene (in)activation. The technique has limited use 222 in C. elegans owing to the canonical Tet system being mostly inactive in the nematode (Mao et al., 223 2019), but has been applied more often in D. melanogaster, since its first use in these fruit flies in 1998 224 (Bello et al., 1998; Bieschke et al., 1998). Beyond these two leading invertebrate models, Tet systems 225 have also been applied in diverse insect species, such as the malaria mosquito Anopheles stephensi 226 (Lycett et al., 2004) and the silkworm B. mori (Karasaki et al., 2009; Tatsuke and Lee, 2013), and tTA227 EGFP vectors have been designed for future applications in a wide range of insect species (Hara et al., $2282008,2009)$.

229 The Tet-On system has further been improved for use in D. melanogaster, with the rtTA-M2-alt version 230 combining a second-generation rtTA that is more sensitive to Dox, is more stable in eukaryotes, and has 231 no background expression (rtTA-M2) (Urlinger et al., 2000) with a fly-optimized rtTA (rtTA-alt). In the 232 fruit fly, rtTA-M2-alt shows lower basal expression levels as well as faster and higher expression upon 233 induction (Stebbins et al., 2001), although there is conflicting evidence concerning the reported higher 234 expression levels (Ford et al., 2007). An additional development is the combination of the Tet system 
with Gal4-UAS (Stebbins et al., 2001; Stebbins and Yin, 2001), as will be further considered when discussing combinatorial techniques later in this manuscript. Only recently has the system been adapted for application in C. elegans, when used in combination with the Q system (Mao et al., 2019), as will also be discussed in more detail in the section on combinatorial approaches.

A disadvantage of all Tet systems is the necessity for the continuous presence of Tet or analogues such as Dox, which could entail side effects and must thus be controlled for in any experimental setup. In addition, expression has been reported in the absence of the drug (Bieschke et al., 1998), although these levels are very low for rtTA-M2-alt (Stebbins et al., 2001). Finally, while in principle, these systems are bidirectional as addition of Tet/Dox can be stopped and thus transcriptional (in)activation would in theory be reversed, recovery periods are uncharacterized for current applications described in invertebrates.

\section{Gal4-UAS and LexA-lexO systems allow for heat- or compound-regulated bidirectional control}

Two conceptually alike binary expression tools are Gal4-UAS and LexA-lexO, which function through use of a transgenic transcription factor and its target sequence (Fig. 4). The Gal4-UAS system is especially popular in the fly community and was first tailored from yeast for use in mammalian cells (Kakidani and Ptashne, 1988; Webster et al., 1988). Gal4 is a transcription activator protein that can bind an enhancer, the upstream activation sequence (UAS), which is followed by a basal promoter ( $h s p 70$ and pes-10 minimal promoters for $D$. melanogaster and $C$. elegans, respectively), and drives transcriptional activation upon binding (Brand and Perrimon, 1993; Wang et al., 2017a). In the literature, UAS usually refers to the combination of the enhancer and basal promoter, so we will also adhere to this notation throughout the review. By expressing Gal4 under control of a tissue-specific or heat shock promoter and placing UAS upstream of a target sequence of interest, the latter can be expressed in a spatially or temporally restricted manner (Fig. 4A). The end result should be much like what it would be when the target sequence is under direct control of these promoters, avoiding the Gal4-UAS intermediate stepin an ideal scenario, it is identical, and in practice, it entails a few controls. As for other binary expression systems, the many advantages of building a flexible resource for use by the international research community have been a major driving force in the continued development of the Gal4-UAS system (del Valle Rodríguez et al., 2012) (more details in the following paragraphs). In 1993, it was applied in D. melanogaster (Brand and Perrimon, 1993), and only much later, in 2016, C. elegans followed (Wang et al., 2017a). The system has further been adapted for use in the red flour beetle T. castaneum, a genetic model more closely related to many insect pest species than $D$. melanogaster (Schinko et al., 
2010). The technology has also been exploited in various insect representatives, such as $A$. aegypti (Kokoza and Raikhel, 2011), Anopheles gambiae (Lynd and Lycett, 2012), A. stephensi (Brochta et al., 2012), and B. mori (Imamura et al., 2003). Gal4 has also seen use in sea urchins (see Table 1 for different species), although only for its DNA binding and transcription activation capacities, and not yet in the context of conditional gene expression (Mao et al., 1996; Bulgakov et al., 2002).

As mentioned previously, the LexA-lexO system functions similar to Gal4-UAS, with a chimeric LexA transcription factor binding and activating its operator lexO (Fig. 4A). In 2000, LexA-lexO was adapted for use in D. melanogaster using the LexA BD fused to the Gal4 activation domain (AD) (Szuts and Bienz, 2000), and later versions instead fused it to the VP16 AD (Lai and Lee, 2006). Its use is more limited owing to the popularity of Gal4-UAS and its plethora of already available driver and reporter lines, but the systems can be applied in parallel to achieve induction of two distinct transgenes in one mosaic animal (Lai and Lee, 2006). Recently, it has been demonstrated that the LexA-lexO system is also active in C. elegans (Nonet, 2020).

In D. melanogaster, Gal4 is usually expressed under the regulation of tissue-specific promoters, allowing for spatial control of gene activation. These driver lines can then be crossed with effector lines containing UAS upstream of a sequence of interest, allowing transcriptional activation in the progeny. Proteins that are toxic, are lethal, or hinder fertility can be investigated this way as the parental driver and effector lines do not express these (Duffy, 2002). Thousands of tissue- or cell-specific Gal4 driver lines have been made available for use by the community (Hayashi et al., 2002; Gohl et al., 2011; Jenett et al., 2012; Tirian and Dickson, 2017; Dionne et al., 2018). For temporal control, a heat shock promoter can be used to express Gal4, but this would imply loss of spatial restriction as brought about by tissuespecific promoters. A technique that circumvents this is Temporal And Regional Gene Expression Targeting (TARGET), which uses the temperature-sensitive Gal4 repressor Gal80 ${ }_{\mathrm{ts}}$ under control of a tissue-specific promoter (McGuire et al., 2003) (Fig. 4B). Heat-dependent versions of Gal4ts can also be used (Mondal et al., 2007). Another widely adopted method is the GeneSwitch system. This uses a modified Gal4 protein that is only active in the presence of the synthetic steroid mifepristone (administrated through feeding or larval bathing), which allows for spatiotemporal control when combined with a tissue-specific promoter (Osterwalder et al., 2001; Scialo et al., 2016) (Fig. 4C). A newer compound-regulated version of Gal4-UAS depends on Gal80-DD, which is similar to Flp-DD discussed previously: Gal80-DD is stable when flies are fed with trimethoprim, but is degraded upon withdrawal from trimethoprim, leading to activation of transcription (Sethi and Wang, 2017) (Fig. 4D). Other options 
for spatiotemporal control include localized heat shock through use of a laser (Halfon et al., 1997) or

298 photoactivation of caged Gal4 (Cambridge, 1997) (Fig. 4E). The Gal4 repressor Gal80 can also be used for refinement of spatial control. Through use of specific promoter combinations for Gal4 and Gal80, expression of the target sequence can be restricted to a smaller subset of cells (Suster et al., 2004). Another technique for intersectional control of gene expression involves splitting Gal4 into its DNA-BD and transcription $A D$, each fused to a leucine zipper fragment to allow reconstitution of the two parts (Fig. 4F). This split-Gal4 makes it possible for each half to be expressed under a different promoter, enabling a more precise spatial control over conditional gene expression (Luan et al., 2006; Pfeiffer et al., 2010; Dionne et al., 2018). Split-Gal4 has been further developed to include the expression of a Killer Zipper (KZip $\left.{ }^{+}\right)$repressor under a third promoter of choice, disrupting the formation of split-Gal4 dimers and subsequent Gal4 activity in a subset of cells (i.e., expressing both Gal4 halves, but not the KZip ${ }^{+}$repressor), allowing for even more accurate spatial regulation (Dolan et al., 2017) (Fig. 4F). Alongside these various possibilities for Gal4 driver lines, different UAS effector lines have been developed with a myriad of uses. Beside standard gain-of-function or rescue constructs, Gal4-UAS has been used for gene knockdown through RNA interference (Kennerdell and Carthew, 2000), for which resources are available containing UAS-driven inverted repeats targeting thousands of genes (Dietzl et al., 2007; Ni et al., 2011). Other applications include cell ablation (UAS::hid and UAS::rpr) (Zhou et al., 1997), attenuation of electrical transmission (UAS::EKO) (White et al., 2001), and inhibition of synaptic vesicle release (UAS::tetanus toxin light chain) (Sweeney et al., 1995). LexA-lexO has also seen several interesting adaptations, such as a Gal-80 suppressible form (when fused to the Gal4 AD) (Lai and Lee, 2006), a split-LexA system (Ting et al., 2011), and, perhaps most interestingly of all, a photoactivatable split-LexA system switched on by blue light (Chan et al., 2015) (Fig. 4G). nematode were unsuccessful, in part owing to its lower $\left(20^{\circ} \mathrm{C}\right)$ culturing temperatures (Wang et al., 2017a). Several alterations in both Gal4 and the UAS resulted in CGAL, a Gal4-UAS system applicable in

322 C. elegans that works robustly at temperatures of $15-25^{\circ} \mathrm{C}$. The system has been verified for use in 323 tissue-specific rescue and gain-of-function experiments (Wang et al., 2017a). Driver lines are available 324 for multiple tissues and individual neurons, and effector lines exist for fluorescent labeling, cell ablation, 325 calcium indication, neuronal activation and inhibition, and inhibition of synaptic vesicle release (Wang 326 et al., 2017a). Similar to D. melanogaster, a split-cGAL has also been developed, using intein domains 327 (which associate, split out, and ligate adjoining peptides) instead of leucine zippers (Wang et al., 2018). 
As mentioned previously, the LexA-lexO system can also be applied in C. elegans (Nonet, 2020), but no further adaptations are available yet in the nematode.

The canonical Gal4-UAS system does not allow for temporal control, making it less useful for flexible conditional expression. In contrast, temperature-dependent systems or the use of heat shock promoters comes with their own issues, as already mentioned. The GeneSwitch system has the limitation of having to add and remove a compound, which has slow activation compared with TARGET: the first is detectable after 3-5 h vs 30 min for the latter, and the GeneSwitch maximal signal was observed after 21-48 h vs $6 \mathrm{~h}$ for TARGET. GeneSwitch has even slower deactivation (up to 6 days vs 1.5 days for TARGET) (Osterwalder et al., 2001; Roman et al., 2001; McGuire et al., 2003) and requires the consideration of leaky expression of a sequence of interest in the absence of mifepristone (McGuire et al., 2003). This is especially true when GeneSwitch is used to induce RNA interference, in which case total protein depletion was observed even when no mifepristone was present (Scialo et al., 2016). A direct experimental comparison between the kinetics, leakiness, and efficiency of the TARGET and GeneSwitch systems would be of interest to allow the community to balance practical considerations for specific experimental purposes. As a final note, when creating new drivers or effectors, it must always be confirmed that these do not affect the process of interest.

\section{6. $Q$ system enables reversible regulation under control of a small molecule}

A binary expression system comparable with Gal4-UAS is the Q system, which was developed for mammalian cells and D. melanogaster by Potter et al. (2010). Its components-QUAS, QF, and QSoriginate from the qa gene cluster of the fungus Neurospora crassa (Potter et al., 2010). The cluster encodes a backup system when glucose levels are low as it allows $N$. crassa cells to catabolize quinic acid (QA) as an alternative carbon source (Giles et al., 1991). QF is the transcriptional activator of this gene cluster and is able to recognize and bind a 16-bp repeated enhancer sequence, QUAS (Patel et al., 1981; Baum et al., 1987), which in the Q system is intended to be transgenically placed upstream of a basal promoter ( $h s p 70$ and pes-10 minimal promoters for D. melanogaster and C. elegans, respectively) and a sequence of interest (Potter et al., 2010; Wei et al., 2012). In conditions wherein QA is absent (or only present at low concentration), the transcriptional suppressor QS can block QF-mediated transcription by binding QF, preventing its interaction with QUAS (Huiet and Giles, 1986). However, when present at higher concentrations, $\mathrm{QA}$ is able to (reversibly) sequester $\mathrm{QS}$, thereby abolishing its interaction with $\mathrm{QF}$ and thus (temporally) restoring transcription from QF-regulated sequences (Giles et al., 1991) (Fig. 5A). The $Q$ system is conceptually identical to the GeneSwitch system. Despite differences in their setup, 
sequences, proteins, and compounds, both allow for temperature-independent temporal control of gene expression through the addition of a small molecule (QA for the Q system [Potter et al., 2010] or mifepristone for GeneSwitch [Osterwalder et al., 2001]). Both systems therefore provide the same advantage over the canonical Gal4-UAS system, but they have not yet been directly compared. Such a comparison could be valuable to the field because it may help researchers decide to choose which system is best suited for their specific research organism or question. To obtain temperatureindependent temporal control of gene expression with the $Q$ system, QA can simply be added to the food source or growth medium of the model organism. Moreover, QA is nontoxic, even in high doses and/or during longtime exposure (Potter et al., 2010). Wei et al. (2012) successfully adapted it for use in C. elegans, and later adoptions of the $Q$ system in other organisms include the disease-carrying mosquito species A. gambiae (Riabinina et al., 2016), Anopheles coluzzii (Afify et al., 2019), and A. aegypti (Matthews et al., 2019), although without inclusion of its temporal control components, that is, QS and QA were not used.

Although temperature-independent temporal control of gene expression was an option, when developed, the $Q$ system in $D$. melanogaster was mainly used for constitutive tissue- or cell-specific transgene expression, mosaic analysis, and cell lineage tracking, as an equivalent to or in combination with the Gal4-UAS system (Potter and Luo, 2011; Mann et al., 2013; Pérez-Garijo et al., 2013; Silies et al., 2013; Riabinina and Potter, 2016). For this purpose, flies in which QF expression is spatially limited to a subset of cells are crossed with flies carrying a transgene under control of QUAS and, if needed, further crossed with flies expressing QS (Potter et al., 2010; Potter and Luo, 2011). In addition, to obtain more targeted spatial control over gene expression, QF can be divided into two fragments, which is referred to as the split-Q system and works similar to split-Gal4 (Luan et al., 2006; Wei et al., 2012; Riabinina et al., 2019) (Fig. 5B). Furthermore, the spatial control of QF-induced gene activation can also be used in the context of conditional gene expression (i.e., in combination with QS and QA) to obtain spatiotemporal control (Potter et al., 2010; Potter and Luo, 2011). However, when expressed too broadly in vivo (e.g., pan-neuronally or ubiquitously), QF appears to be lethal (Potter et al., 2010). To overcome this problem, improved versions of QF have been designed, QF2 and QF2 ${ }^{\text {weaker) }}$, which no longer contain the apparent major source of in vivo toxicity: the QF middle domain. Both improved versions remain fully active, yet QF2 ${ }^{\mathrm{w}}$ is a weaker transcriptional activator than QF2, and it is more susceptible to repression by QS. Ubiquitous expression of the stronger activator QF2 appears to still have deleterious health effects, suggesting that next to global expression, the degree of QF activity also contributes to its in vivo toxicity. Together, these results imply QF2 ${ }^{\mathrm{w}}$ is of more general use as it is more 
suitable for broad expression, whereas QF2 may be preferred only when weaker tissue-specific

392 promoters are used (Riabinina et al., 2015). All versions of the transcriptional activator (QF, QF2, and QF2 ${ }^{\mathrm{w}}$ ) can be used in the context of the previously mentioned split-Q system and are suitable for application in conditional gene expression experiments as they are all prone to QS-induced repression, which can be reversed by QA (Riabinina et al., 2015, 2019). The extent of the effect of QA-induced gene activation is dose dependent, but the temporal on-dynamics are relatively constant: in adult flies, expression can be observed after $6 \mathrm{~h}$, reaching relatively high levels after $24 \mathrm{~h}$, and after about 3 days, saturation occurs (Potter et al., 2010; Riabinina and Potter, 2016).

Application of the $Q$ system in C. elegans did not require major adaptations, except for the incorporation of the $\triangle p e s-10$ minimal promoter downstream of the QUAS repeats, to allow for initiation of QF-induced

402 improved versions of QF, QF2, and QF2w, in C. elegans (Aoki et al., 2018; Nonet, 2020). Analogous to 403 D. melanogaster, by using tissue- or cell-specific promoters, the $Q$ system also allows for spatial control 404 of gene expression in C. elegans. In fact, the split-Q system was initially developed in the latter organism 405 (Wei et al., 2012). Regarding temporal dynamics of transcriptional derepression by QA, experiments in C. elegans-perhaps unsurprisingly so-outperform those in D. melanogaster, that is, expression of QFregulated genes can be observed after $6 \mathrm{~h}$ of exposure, with saturation occurring after $24 \mathrm{~h}$ (Wei et al., 2012). Yet, for some biological processes, this time frame is not sufficient (e.g., developmental events or rapid cellular processes). Therefore, in C. elegans, the $Q$ system tool kit was extended with the

411 The activity of this so-called QF-GR is regulated by the presence of dexamethasone, a glucocorticoid.

412 This ligand-gated QF-mediated transcription is more rapid than the conventional derepression of gene 413 expression by QS-QA: using dexamethasone, gene expression can already be observed two hours after 414 starting the treatment (Fig. 5C). The available version of this system still suffers from considerable 415 uninduced activation of QF-GR (Monsalve et al., 2019), which is why it currently relies on additional 416 repression by QS (and derepression by QA), irrespective of the presence of dexamethasone. Once this 417 un-induced activation would be resolved, an exciting prospect of this system is a more refined spatial 418 restriction of expression by driving QS (slow dynamics) and QF-GR (fast dynamics) by distinct tissue- or 419 cell-specific promoters, that is, dexamethasone should then only activate QF-GR in cells where QS is 420 absent. 
421 The $\mathrm{Q}$ system is independent of temperature for temporal control, avoiding several common drawbacks

422 as explained before. Instead, after administration, QA is taken up by the cells where it induces QF-based 423 transcription through interaction with QS (Potter et al., 2010). However, not all cells may be able to take 424 up QA equally efficiently, which is especially the case in organisms with a blood-brain barrier as this 425 impedes diffusion of QA (Riabinina and Potter, 2016). For example, in D. melanogaster, the peripheral 426 neurons, which are in direct contact with hemolymph, exhibit a stronger QA-induced effect than central 427 brain neurons (Riabinina et al., 2015; Riabinina and Potter, 2016). In addition, it is still undefined what 428 time it might take for the QA-induced transcription to be effectively repressed again by QS after QA is 429 removed. This is especially of interest for experiments in which a transgene needs to be switched on 430 only for a short period of time. It has also been reported that QS does not fully suppress QF when 431 present in a 1:1 ratio, which could easily lead to leaky expression from QF-regulated genes (Potter et al., 432 2010). On the other hand, too great an excess of QS may be suboptimal as well as it has already been 433 demonstrated that derepression of transcription by QA is not highly efficient, that is, QA is not able to 434 fully inactivate QS (Potter et al., 2010; Wei et al., 2012). Therefore, finding the right balance between QF 435 and QS is a crucial part when implementing and using the $Q$ system.

\section{Combinatorial approaches broaden the applicability of conditional gene expression}

437 The genetic tool kits of invertebrate model organisms include various systems whose distinct components can be used interchangeably, thereby generating combinatorial systems that further 439 improve the individual systems (Fig. 6).

$440 \quad 7.1$ Combining Tet and Gal4-UAS systems for increased spatial (and temporal) control in D. melanogaster 441 A major drawback of the Gal4-UAS system is the lack of temperature-independent temporal control of 442 gene expression. While this issue is largely overcome in the GeneSwitch (Osterwalder et al., 2001; Scialo 443 et al., 2016) system, in some $D$. melanogaster tissues Gal4 is relatively unresponsive to mifepristone444 mediated activation, as there appears to be leaky activity of the transcriptional activator (Poirier et al., 445 2008). Combinations of elements from two conditional systems can alternatively be used to enable 446 temperature-independent temporal control, for example, thanks to a Tet-Off driven Gal80 transgene. In 447 the absence of an inducer (Tet or Dox), tTA is able to bind the tet operator, from which it promotes 448 transcription of the Gal4 repressor, Gal80. As such, transcriptional inhibition of the Gal4-regulated 449 transgene can be lifted by addition of Tet or Dox, which prevent tTA from interacting with tetO (Barwell et al., 2017) (Fig. 6A). This Tet-Off Gal80 system is not the only example of Tet and Gal4-UAS systems 
combinations. In 2001, Stebbins et al. already reported on flies carrying spatially restricted Gal4 that drives the expression of tTA (Stebbins and Yin, 2001) or rtTA (Stebbins et al., 2001), which are able to regulate transcription of a sequence of interest downstream of tetO. The rationale to establish this combination was to tackle the issue of the relative lack of ( $r$ )tTA driver lines compared to the abundant presence of Gal4 driver lines at that time, and thus significantly increase the options for spatial control over gene expression when temporal control is already secured via the Tet system. Making use of the available Gal4 resource avoided the need for the labor-intensive engineering of countless new ( $r$ tTA drivers (Stebbins et al., 2001; Stebbins and Yin, 2001).

A considerable issue with the $Q$ system is the inefficiency of transcriptional derepression, that is, suppression by QS is not fully abolished after treatment with QA (Potter et al., 2010; Wei et al., 2012). To tackle this problem, Mao et al. (2019) adapted the Tet system for application in C. elegans by combining it with components of the $Q$ system, resulting in a hybrid system that appears to be more robust and flexible than both the individual predecessors. The rationale for this combination with the Tet system is the relatively highly efficient interaction between ( $r)$ tTA and Dox or Tet compared with the QS-QA interaction. However, as mentioned earlier, the canonical Tet-controlled system appears to be largely inactive in the nematode, presumably because the VP16 transactivation domain of (r)tTA and the $\mathrm{CMV}$ minimal promoter that are combined with the tet operator are derived from human viruses. In other words, both components have probably evolved to specifically interact with the human transcription machinery, making them less functional in nematodes (Mao et al., 2019). Therefore, In the Tet/Q Hybrid system, the VP16 transactivation domain and the CMV minimal promoter are replaced by components that are known to be active in C. elegans (Wei et al., 2012), allowing the system to be applicable in this worm: the hybrid reverse transactivator, $\operatorname{rtTA}(Q)$, consists of the Dox-inducible reverse TetR fused to the AD of QF, and the modified TRE includes tetO upstream of the $\triangle p e s-10$ minimal promoter (Mao et al., 2019). To avoid leaky expression from the modified TRE in the absence of Dox, a tetracycline-regulated transcriptional silencer (tTS) is introduced, which consists of TetR fused to PIE-1, an inhibitor of RNA polymerase II (Ghosh and Seydoux, 2008; Mao et al., 2019). As such, the general activity of the Tet/Q Hybrid system is controlled by Tet or Dox. Their presence induces $\operatorname{rtTA}(Q)$ and suppresses tTS, allowing mRNA production from the modified TRE, whereas in their absence, transcription is not activated and even effectively silenced by tTS (Mao et al., 2019) (Fig. 6B). Furthermore, because $\operatorname{rtT}(\mathrm{Q})$ comprises the $\mathrm{QF} A D$, an additional level of control can be achieved by 
482

coexpressing a (spatially restricted) QS repressor construct, of which the activity can be temporally regulated by QA (Wei et al., 2012; Mao et al., 2019).

7.3 D. melanogaster chimeric $Q$ systems exchange temperature for $Q A$ as means of temporal control Analogous to $\operatorname{rtTA}(\mathrm{Q})$ of the Tet/Q Hybrid system, other chimeric transactivators have been generated through fusion of a DNA-BD to the activation domain of QF, including Gal4QF (Riabinina et al., 2015) and LexAQF (Riabinina et al., 2015). Both hybrid components are of particular interest as they allow for a GAL80 (ts)-independent suppression of UAS-controlled transcription, that is, through QS (Fig. 6C). As such, temporal control over gene expression can be obtained by adding QA instead of by increasing temperature, which is a significant improvement for the Gal4-UAS and LexA-lexO systems in D. melanogaster (Riabinina et al., 2015).

\subsection{Temporal control over recombinase activation}

In a previous section, it was mentioned that Cre-LoxP and Flp-FRT do not allow for temporal control, unless used in combination with a heat shock promoter. However, with the myriad of inducible expression techniques available nowadays, this statement is not entirely correct: expression of the recombinase enzyme could be temporally controlled by all previously described systems as well. Yet, to date, there have only been reports of Flp or Cre recombinase genes being expressed under control of Gal4-UAS in D. melanogaster (Frickenhaus et al., 2015) and the Tet/Q Hybrid system in C. elegans (Mao et al., 2019). Although the result of the enzymatic action remains irreversible, in these animals, Flpmediated DNA recombination is induced upon temperature-dependent inactivation of Gal80 (Frickenhaus et al., 2015) (Fig. 6D) or Cre is activated by addition of Dox (Mao et al., 2019).

\section{Post-transcriptional approaches provide an additional level of control}

So far, we have discussed techniques with a direct effect at the genetic (Cre-LoxP and Flp-FRT) or transcriptional (heat shock-related induction, Tet, Gal4-UAS and Q system) level of gene expression. Yet, conditional RNA or protein availability can also be established through post-transcriptional control. We here wish to discuss - albeit briefly - the various post-transcriptional techniques that are available for use in invertebrate models. Some such techniques are already commonly used (e.g., reviewed in the studies by Nance and Frøkjær-Jensen, 2019 and Trauth et al., 2019); although others are relatively new to the field, they show great promise for more widespread use. 
One aspect of the post-transcriptional level of gene expression is the conditional control of RNA

511 availability, which can be obtained using riboswitches or RNA interference. On the other hand, there is

512 the protein aspect, which includes two main approaches: targeted degradation and trapping of proteins,

513 both of which comprise a various number of techniques, as will be briefly introduced in the following

514 sections.

$515 \quad 8.1$ Tight bidirectional control over mRNA availability by using a self-cleaving ribozyme switch in

516 C. elegans

517 Riboswitches are regulatory elements in mRNA that are able to control the availability of their respective

518 strand. Because they exist as secondary structures, their regulatory function can be affected by

519 structural changes induced by external factors, including certain ligands that are able to bind a

520 riboswitch-associated aptamer domain (Batey, 2006). By consequence, bidirectional conditional control

521 over a sequence of interest can be obtained by transgenically incorporating a riboswitch sequence.

522 Although an exciting prospect for conditional control over mRNA availability, only a single riboswitch-

523 based tool has been reported in invertebrate model organisms so far: a Tet-dependent ribozyme switch

524 adapted from human cell culture for use in C. elegans (Wurmthaler et al., 2019). This specific riboswitch

525 exists as an aptamer-containing self-cleaving ribozyme in the $3^{\prime}$-untranslated region of a sequence of

526 interest, and its mechanism of action allows for tight bidirectional control over gene expression. In the

527 absence of the ligand, Tet, the enzymatic activity of the ribozyme is induced, causing it to make a single

528 cut in one of its own stem-loop structures, eventually resulting in mRNA decay of the sequence of

529 interest. However, in the presence of Tet, ribozyme activity is repressed and the mRNA remains intact,

530 allowing it to be translated into protein (Wurmthaler et al., 2019). The main advantage of using a

531 riboswitch over conditional gene expression is that typically fewer genetic manipulations are required

532 than the approaches mentioned before. Yet, a considerable drawback is that riboswitches are inherently

533 limited to the temporal level of control, that is, transgenic incorporation of a tissue-specific promoter

534 would be required to spatially restrict the expression of the target gene.

\subsection{Targeted mRNA degradation through RNA interference}

536 A frequently used technique that could be considered a form of post-transcriptional conditional

537 expression is RNA interference, in which double-stranded RNA sequences are used to target and 538 degrade specific mRNAs of interest. This approach is widespread and applied in practically all

539 (invertebrate) model organisms. There are several ways to conditionally induce RNA interference, 
540 including via the conditional expression systems described earlier in this review. For an explanation of

541 the mechanism of action and application potential of RNA interference itself, we refer the reader to

542 existing thorough reviews by Xu et al. (2019) and Ahringer (2006).

\subsection{Protein degradation bypasses transcription and translation to rapidly inactivate target proteins}

544 While the systems discussed up to now focus on regulating the production of a protein of interest, there is also the possibility to control their presence by focusing on the degradation of existing proteins. The most popular way to achieve this is through tagging with a degron domain. This degron is recognized

547 and bound by an F-box protein, recruiting it to the E3 ubiquitin-protein ligase complex that ubiquitinates

548 the protein, thus targeting it to the proteasome for breakdown. An early example in both

549 D. melanogaster and C. elegans is deGradFP: a protein of interest is transgenically tagged with a GFP

550 degron, which is targeted by a GFP nanobody fused to a component of the E3 complex, allowing 551 ubiquitination and subsequent degradation (Caussinus et al., 2012; Wang et al., 2017b). In another

552 C. elegans system, proteins tagged with zinc-finger domain 1 are bound by zinc finger-interacting

553 factor 1, which forms part of the E3 ubiquitin-protein ligase complex and thus leads to protein 554 degradation (Armenti et al., 2014). Protein degradation can also be controlled by compounds, heat, or 555 light. A widely used compound-based system applicable in both $D$. melanogaster and $C$. elegans is the 556 plant-derived auxin-inducible degradation system. In this system, the auxin-activated F-box protein TIR1 557 is responsible for detecting degron sequences, leading to ubiquitination and protein depletion in the 558 presence of the plant hormone auxin (Zhang et al., 2015; Trost et al., 2016). A deGradFP variant in 559 C. elegans allows for drug-induced protein depletion. In this method, the GFP nanobody and E3 complex 560 are separated and fused to chemically induced dimerization domains, which allow for ligation upon 561 induction by rapamycin, thus resulting in depletion of the target protein (Deng et al., 2020). Alternative 562 to degrons, DDs can be used, which are only stable when in the presence of trimethoprim and lead to 563 the degradation of any attached protein upon removal of the ligand. This has been applied in both 564 D. melanogaster and C. elegans (Cho et al., 2013; Sethi and Wang, 2017). As for heat-regulated 565 techniques, a low-temperature-controlled degron has been designed for $D$. melanogaster, which 566 induces degradation of the protein it is fused to when switching from $15^{\circ} \mathrm{C}$ to $29^{\circ} \mathrm{C}$ (Faden et al., 2016). A

567 C. elegans temperature-driven technique depends on the tagging of proteins with a LPETG peptide 568 sequence, the ubiquitous expression of a heptamutant Staphylococcus aureus Sortase A (SrtA $\left.A_{7 m}\right)$, and 569 the heat shock promoter-regulated expression of a tri-glcyine tagged F-box protein ( $\left.\mathrm{G}_{3}-\mathrm{F}-\mathrm{box}\right)$. Upon 570 heat shock, $\mathrm{G}_{3}-\mathrm{F}-$-box is expressed. SrtA $\mathrm{Am}_{7 \mathrm{~m}}$ will attach this $\mathrm{G}_{3}-\mathrm{F}-$-box to the tagged protein of interest, 
571 marking it for degradation by the proteasome (Wu et al., 2017). Finally, light can be used as a stimulus.

572 In C. elegans, there is a degron-independent light-regulated system that relies on fusing a miniature

573 singlet oxygen generator (miniSOG) to a protein of interest to enable chromophore-assisted light

574 inactivation. When illuminated with blue light, miniSOG generates reactive oxygen species, which in this

575 setup destroy the protein that miniSOG is attached to (Lin et al., 2013). A more recent $C$. elegans light-

576 based system uses a photosensitive degron, which activates protein degradation upon low-intensity

577 blue light illumination, and is more specific than the miniSOG system, which can unwantedly affect the

578 nearby proteins (Hermann et al., 2015). The major advantage of protein degradation over all the other

579 techniques described is its speed. While other systems rely on transcription, translation, and protein

580 turnover, protein degradation directly targets and inactivates the final product. However, these systems

581 are often more complex, requiring specific transgenic strains for each experiment, sometimes containing

582 multiple transgenes. Thus, there are no vast libraries of genetic resources available, as is the case for

583 recombinase or Gal4-UAS-based systems. Moreover, these systems generally rely on fusing the protein

584 of interest to a degron or other tag, which can in itself interfere with the stability or function of the

585 protein (Kerk et al., 2017; Patel and Hobert, 2017).

8.4 Protein trapping as alternative to degradation

587 Instead of completely degrading a protein of interest, the protein can also be conditionally targeted to

588 an abnormal subcellular location, thus interfering with its usual activity. This can be useful to investigate

589 whether the localization of the protein is important to its function. The morphotrap system in

590 D. melanogaster and C. elegans relies on a membrane-tethered GFP nanobody that traps GFP-tagged

591 proteins of interest, keeping them at the membrane (Harmansa et al., 2015; Pani and Goldstein, 2018).

592 In C. elegans, this has been further developed into a photoinducible system. Here, the protein of interest

593 is tagged with a light-activated membrane anchor, localizing it to the membrane upon blue light

594 illumination (Fielmich et al., 2018). The (dis)advantages of this system are similar to those described

595 previously for protein degradation, with the added consideration that the protein may have residual or

596 altered function at its ectopic location.

\section{9. Future developments promise a further expansion of the invertebrate genetic tool kit}

598 A large variety of methods for transcriptional control of gene expression is currently available for use in 599 invertebrate model organisms (summarized in Table 1). However, a drawback of the most novel method 600 among them is the relative lack of available driver lines and/or reporter strains (Stebbins et al., 2001; 
601

602

603

604

605

606

607

608

609

610

611

612

613

614

615

616

617

618

619

620

621

622

623

624

625

626

627

628

629

630

631

Gohl et al., 2011; Wei et al., 2012; Lin and Potter, 2016; Riabinina and Potter, 2016). Nevertheless, as these systems have already proven their efficacy in these organisms, this issue will likely resolve itself in the near future, as has formerly been the case, for example, with the already well-established Gal4-UAS system (Hayashi et al., 2002; Gohl et al., 2011; Jenett et al., 2012; Tirian and Dickson, 2017; Dionne et al., 2018). Moreover, as current methods permit exchange of transcription factors of existing driver lines with those of other systems, this could proceed even faster (Gohl et al., 2011; Lin and Potter, 2016). We can thus expect to see a continued growth of the invertebrate strain collection to support experiments relying on transcriptional conditional genetics. Furthermore, new post-transcriptional techniques acting at the RNA and protein level are providing an additional means to control protein availability, with their own set of novel applications and challenges.

Many of the systems described here have not yet reached their full potential in (all or even major only) invertebrate model organisms. Site-directed recombinases are particularly popular in mice and mammalian cells, where they have seen a plethora of further adaptations not yet fully exploited in invertebrates. A frequently used example is the previously described FLEx switch (Schnütgen et al., 2003), which has seen limited use in D. melanogaster and has to our knowledge not yet been applied in C. elegans. Other examples include the use of inverted-repeat loxP site variants that can only recombine once and are then locked in their new orientation (Araki et al., 1997), combining Cre-LoxP and Flp-FRT for more precise control of gene expression (Kim et al., 2009) and using a drug-dependent Cre fusion protein for temporal control (Feil et al., 1997). Gal4-UAS has already seen extensive use in D. melanogaster but has only recently been adapted for C. elegans. With CGAL now available, we can expect to see many further variations of the system in C. elegans that have already been developed in D. melanogaster, such as the GeneSwitch system and the combination with Gal80. Although it was first introduced in D. melanogaster (Potter et al., 2010), the Q system tool kit is a little more extensive in C. elegans, in which QF-GR allows for additional ligand-gated control of transcription (Monsalve et al., 2019). In the near future, this LBD-fused QF will presumably be adapted for use in other organisms as well. Similarly so, combinatorial approaches are generally relatively recent techniques, which to date have mainly been used in only one organism (Stebbins et al., 2001; Stebbins and Yin, 2001; Riabinina et al., 2015; Mao et al., 2019). We therefore predict that their application will shortly be expanded to a broader range of invertebrate model organisms. Finally, the post-transcriptional approaches have also got a lot of potential left for further development, which we expect will be taken advantage of in the near future. For example, to date, only a single riboswitch-based tool has been adapted for use in 
632 invertebrates (only in C. elegans), whereas multiple such systems have been developed for use in 633 vertebrates (Felletti and Hartig, 2017).

634 Most conditional expression systems rely on heat or small compounds for temporal control, which limit 635 their use in experimental setups. With the advent of optogenetics, new possibilities arise, especially in 636 transparent invertebrates such as $C$. elegans or the translucent larval stages of $D$. melanogaster. Already 637 developed are the photoactivatable split-Cre (Boulina et al., 2013), Gal4 (Cambridge, 1997), and LexA 638 (Chan et al., 2015) systems in D. melanogaster and the photoactivatable Cre (Davis et al., 2020), 639 miniSOG (Lin et al., 2013), and degron (Hermann et al., 2015) systems in C. elegans. In vertebrate cell 640 cultures, a plethora of such systems have been developed (Hörner et al., 2017), based on light-inducible 641 recombinases (Weinberg et al., 2019), Tet transactivators (Müller et al., 2014; Yamada et al., 2018), Gal4 642 (Shimizu-Sato et al., 2002; Wang et al., 2012), diverse other transcriptional activators (Polstein and 643 Gersbach, 2012; Konermann et al., 2013), and clustered regularly interspaced short palindromic 644 repeats/CRISPR-associated protein 9 (CRISPR/Cas9) (Nihongaki et al., 2015; Polstein and Gersbach, 645 2015). Optogenetic systems have even been combined to create a multichromatic expression tool that 646 can activate three separate genes in one cell culture depending on the wavelength of light used (Müller et al., 2013). Some of the aforementioned systems have also been applied in vivo in mammalian models, 648 either through optical implants (Konermann et al., 2013; Yamada et al., 2018) or through direct external 649 illumination (Wang et al., 2012); however, this is more technically challenging than is the case for 650 translucent organisms. Adapting these systems for invertebrates would deliver important advantages 651 compared with most current tools for conditional genetics: less unwanted side effects, rapid on-off

652 switching, and spatial precision using focused light sources. The transparency of $C$. elegans and 653 translucency of larval D. melanogaster is an additional great benefit, and we look forward to seeing the 654 future applications of optogenetic gene expression in these invertebrate models.

655 A gene editing tool that has revolutionized the world of molecular biology over the past decade is 656 CRISPR-Cas9, in which a complex consisting of a Cas9 nuclease and guide RNA is directed to a specific 657 genomic site where the nuclease cuts the DNA, allowing for highly targeted mutagenesis. Recent years 658 have seen the adaptation of CRISPR for conditional gene expression, especially in mammalian cell lines 659 and mice. A first way to achieve this is by simply regulating the expression of Cas9 or guide RNA using 660 one of the already discussed systems, such as the Tet system (Aubrey et al., 2015; Dow et al., 2015), 661 recombinases (Chylinski et al., 2019), or ribozymes (Tang et al., 2017). A second approach involves modifying the Cas9 protein or guide RNA itself, making it inducible by a small molecule (Davis et al., 
2015; Zetsche et al., 2015; Wang et al., 2020) or by light (Nihongaki et al., 2015; Polstein and Gersbach, 2015; Jain et al., 2016). These concepts are also spreading to invertebrate communities, primarily to research relying on $D$. melanogaster. As in mammals, existing systems can be applied to obtain conditional control over Cas9 or guide RNA; so far, this has been carried out using Gal4-UAS (Port and Bullock, 2016) and TARGET (Port et al., 2020b). In addition, Gal4-UAS has been applied to drive CRISPRCas9-based transcriptional activation (CRISPRa). This novel approach depends on a UAS-controlled nuclease-dead Cas9 (dCas9) fused to a transcriptional activator, which can bind a target DNA sequence complementary to a guide RNA, where it activates transcription of a sequence of interest (Lin et al., 2015). A more recent combination of Gal4-UAS and CRISPRa in D. melanogaster is the synergistic activation mediator technique (flySAM), which consists of a UAS-driven dCas9 activator, a modified guide RNA containing two hairpin aptamers, and a tripartite fusion of an aptamer-binding subunit, a trans-activating subunit, and an AD. The addition of this latter fusion protein greatly improves transcriptional activation (Jia et al., 2018). In addition, engineering Cas9 in such a way that it can act conditionally, independently of any other systems, is making its way into invertebrate research. For example, Cas9 can be fused to the progesterone ligand-BD, resulting in a mifepristone-inducible Cas9 protein, similar to the GeneSwitch system (Huynh et al., 2018). In yet another conditional CRISPR system, a temperature-dependent Cas12a is used, which is inactive at $18^{\circ} \mathrm{C}$ and active at $29^{\circ} \mathrm{C}$ (Port et al., 2020a). In C. elegans, only heat shock promoters have been used to conditionally express Cas9 (Shen et al., 2014), although simply feeding these worms with guide RNA at a specific moment allows for temporal control as well (Liu et al., 2014). These conditional CRISPR-Cas9 systems allow for a wider variety of interventions than classical conditional systems-instead of simply turning an entire gene on or off, single nucleotides, specific regulatory elements, or protein domains can be targeted in a temporally restricted manner. For example, by mutating only the catalytic site, protein function can be abrogated without having to get rid of the protein altogether. Owing to this broader application potential, we can expect to see the systems already available in vertebrates being introduced in invertebrates, as well as those already established in $D$. melanogaster spreading to other invertebrate organisms.

In current research relying on invertebrates, most of the techniques are primarily applied in D. melanogaster and C. elegans, which makes sense as these represent the largest research communities. However, in recent years, the availability of cheap genome sequencing has led to an explosion in the number of available genomes. Together with the expansion of genetic methodologies, functional genetics is now possible in organisms other than the 'classical' model organisms, which forms 
a great advantage to scientific research. An essential future development would therefore be to adapt the techniques for conditional gene expression-classic and novel-that are already well established in a few mammalian or invertebrate representatives, to be applicable in a much wider range of organisms. The most basic forms of all the methods mentioned here have already been applied in some other invertebrate species, and it is likely for the adapted versions to transition into applications in such other species as well. Considerations that must be taken into account when applying these systems in a 'new' model include the absence of endogenous recognition sequences when using transgenic enzymes and transcription factors, the potential toxicity of enzymes involved in these systems in their new cellular and organismal contexts, and possible side effects of heat, compounds, or light used for (in)activation.

The combination of fast genetics in invertebrates and the extensive tool kit for conditional gene expression reviewed here has already shown to be of great value to the research community. Many of these systems are rapidly gaining popularity, indicating their importance to the field, that is, there is a myriad of research questions for which these systems can be used. However, we will only be able to address several other research questions when further improving the temporal resolution and spatial precision of control, that is, despite the extensiveness of the tool kit, many of the available systems have too slow dynamics or act too widely to be able to tackle extremely fast and/or local processes. We therefore predict that the future of the field lies not in the use of compounds, but rather in the use of light (optogenetics), which is fast and can be administered with high precision. By controlling gene expression as tightly as possible, we will be able to answer even more research questions, thus further unraveling the fundamentals of life.

\section{Acknowledgements}

We thank Areta Jushaj for critical reading of the manuscript. B.D. and L.M. are fellows of the FWO Flanders. This study was supported by Horizon 2020 grant 633589, FWO Flanders grant G052217N, and KU Leuven grant C16/19/003. The funding sources had involvement neither in the writing of the review nor in the decision to submit the article for publication.

\section{References}

Afify, A., Betz, J.F., Riabinina, O., Lahondère, C., Potter, C.J., 2019. Commonly Used Insect Repellents Hide Human Odors from Anopheles Mosquitoes. Curr. Biol. 29, 3669-3680. https://doi.org/10.1016/j.cub.2019.09.007

Ahringer, J., 2006. Reverse genetics, in: The C. elegans Research Community (Ed.), WormBook. WormBook. https://doi.org/10.1895/wormbook.1.47.1 
Aoki, W., Matsukura, H., Yamauchi, Y., Yokoyama, H., Hasegawa, K., Shinya, R., Ueda, M., 2018. Cellomics approach for high-throughput functional annotation of Caenorhabditis elegans neural network. Sci. Rep. 8, 10380. https://doi.org/10.1038/s41598-018-28653-x

Araki, K., Araki, M., Yamamura, K.I., 1997. Targeted integration of DNA using mutant lox sites in embryonic stem cells. Nucleic Acids Res. 25, 868-872. https://doi.org/10.1093/nar/25.4.868

Armenti, S.T., Lohmer, L.L., Sherwood, D.R., Nance, J., 2014. Repurposing an endogenous degradation system for rapid and targeted depletion of $C$. elegans proteins. Development 141, 4640-4647. https://doi.org/10.1242/dev.115048

Aubrey, B.J., Kelly, G.L., Kueh, A.J., Brennan, M.S., O’Connor, L., Milla, L., Wilcox, S., Tai, L., Strasser, A., Herold, M.J., 2015. An Inducible Lentiviral Guide RNA Platform Enables the Identification of TumorEssential Genes and Tumor-Promoting Mutations In Vivo. Cell Rep. 10, 1422-1432. https://doi.org/10.1016/j.celrep.2015.02.002

Bacaj, T., Shaham, S., 2007. Temporal Control of Cell-Specific Transgene Expression in Caenorhabditis elegans. Genetics 176, 2651-2655. https://doi.org/10.1534/genetics.107.074369

Bapst, A.M., Dahl, S.L., Knöpfel, T., Wenger, R.H., 2020. Cre-mediated, loxP independent sequential recombination of a tripartite transcriptional stop cassette allows for partial read-through transcription. Biochim. Biophys. Acta - Gene Regul. Mech. 1863, 194568. https://doi.org/10.1016/j.bbagrm.2020.194568

Barwell, T., DeVeale, B., Poirier, L., Zheng, J., Seroude, F., Seroude, L., 2017. Regulating the UAS/GAL4 system in adult Drosophila with Tet-off GAL80 transgenes. PeerJ 5, e4167. https://doi.org/10.7717/peerj.4167

Batey, R.T., 2006. Structures of regulatory elements in mRNAs. Curr. Opin. Struct. Biol. 16, 299-306. https://doi.org/10.1016/j.sbi.2006.05.001

Baum, J.A., Geever, R., Giles, N.H., 1987. Expression of qa-1F activator protein: identification of upstream binding sites in the qa gene cluster and localization of the DNA-binding domain. Mol. Cell. Biol. 7, 1256-1266. https://doi.org/10.1128/MCB.7.3.1256

Bello, B., Resendez-perez, D., Gehring, W.J., 1998. Spatial and temporal targeting of gene expression in Drosophila by means of a tetracycline-dependent transactivator system. Development 125, 21932202.

Bieschke, E.T., Wheeler, J.C., Tower, J., 1998. Doxycycline-induced transgene expression during Drosophila development and aging. Mol. Gen. Genet. MGG 258, 571-579. https://doi.org/10.1007/s004380050770

Boulina, M., Samarajeewa, H., Baker, J.D., Kim, M.D., Chiba, A., 2013. Live imaging of multicolor-labeled cells in Drosophila. Development 140, 1605-1613. https://doi.org/10.1242/dev.088930

Brand, A.H., Perrimon, N., 1993. Targeted gene expression as a means of altering cell fates and generating dominant phenotypes. Development 118, 401-415.

Broach, J.R., Hicks, J.B., 1980. Replication and recombination functions associated with the yeast plasmid, $2 \mu$ circle. Cell 21, 501-508. https://doi.org/10.1016/0092-8674(80)90487-0

Brochta, D.A.O., Pilitt, K.L., Harrell, R.A., Aluvihare, C., Alford, R.T., 2012. Gal4-based Enhancer-Trapping 
in the Malaria Mosquito Anopheles stephensi. G3 (Bethesda) 2, 1305-1315. https://doi.org/10.1534/g3.112.003582

Bulgakov, V.P., Odintsova, N.A., Plotnikov, S. V, Kiselev, K. V, Zacharov, E. V, Zhuravlev, Y.N., 2002. Gal4Gene-Dependent Alterations of Embryo Development and Cell Growth in Primary Culture of Sea Urchins. Mar. Biotechnol. 4, 480-486. https://doi.org/10.1007/s10126-002-0036-7

Cambridge, S.B., 1997. Drosophila Mitotic Domain Boundaries as Cell Fate Boundaries. Science 277, 825828. https://doi.org/10.1126/science.277.5327.825

Caussinus, E., Kanca, O., Affolter, M., 2012. Fluorescent fusion protein knockout mediated by anti-GFP nanobody. Nat. Struct. Mol. Biol. 19, 117-121. https://doi.org/10.1038/nsmb.2180

Chan, Y.-B., Alekseyenko, O. V., Kravitz, E.A., 2015. Optogenetic Control of Gene Expression in Drosophila. PLoS One 10, e0138181. https://doi.org/10.1371/journal.pone.0138181

Chen, X., Liao, S., Huang, X., Xu, T., Feng, X., Guang, S., 2018. Targeted Chromosomal Rearrangements via Combinatorial Use of CRISPR/Cas9 and Cre/LoxP Technologies in Caenorhabditis elegans. G3 (Bethesda) 8, 2697-2707. https://doi.org/10.1534/g3.118.200473

Chen, X., Tan, A., Palli, S.R., 2020. Identification and functional analysis of promoters of heat-shock genes from the fall armyworm, Spodoptera frugiperda. Sci. Rep. 10, 2-10. https://doi.org/10.1038/s41598-020-59197-8

Cho, U., Zimmerman, S.M., Chen, L., Owen, E., Kim, J. V., Kim, S.K., Wandless, T.J., 2013. Rapid and Tunable Control of Protein Stability in Caenorhabditis elegans Using a Small Molecule. PLoS One 8, e72393. https://doi.org/10.1371/journal.pone.0072393

Chylinski, K., Hubmann, M., Hanna, R.E., Yanchus, C., Michlits, G., Uijttewaal, E.C.H., Doench, J., Schramek, D., Elling, U., 2019. CRISPR-Switch regulates sgRNA activity by Cre recombination for sequential editing of two loci. Nat. Commun. 10, 5454. https://doi.org/10.1038/s41467-01913403-y

Davis, K.M., Pattanayak, V., Thompson, D.B., Zuris, J.A., Liu, D.R., 2015. Small molecule-triggered Cas9 protein with improved genome-editing specificity. Nat. Chem. Biol. 11, 316-318. https://doi.org/10.1038/nchembio.1793

Davis, L., Radman, I., Goutou, A., Tynan, A., Baxter, K., Xi, Z., Chin, J.W., Greiss, S., 2020. Optically splitting symmetric neuron pairs in $C$. elegans. Preprint on bioRxiv. https://doi.org/10.1101/2020.05.02.072363

Davis, M.W., Morton, J.J., Carroll, D., Jorgensen, E.M., 2008. Gene Activation Using FLP Recombinase in C. elegans. PLoS Genet. 4. https://doi.org/10.1371/journal.pgen.1000028

del Valle Rodríguez, A., Didiano, D., Desplan, C., 2012. Power tools for gene expression and clonal analysis in Drosophila. Nat. Methods 9, 47-55. https://doi.org/10.1038/nmeth.1800

Deng, W., Bates, J.A., Wei, H., Bartoschek, M.D., Conradt, B., Leonhardt, H., 2020. Tunable light and drug induced depletion of target proteins. Nat. Commun. 11, 304. https://doi.org/10.1038/s41467-01914160-8

Didomenico, B.J., Bugaisky, G.E., Lindquist, S., 1982. The heat shock response is self-regulated at both the transcriptional and posttranscriptional levels. Cell 31, 593-603. https://doi.org/10.1016/0092- 
Dietzl, G., Chen, D., Schnorrer, F., Su, K.-C., Barinova, Y., Fellner, M., Gasser, B., Kinsey, K., Oppel, S., Scheiblauer, S., Couto, A., Marra, V., Keleman, K., Dickson, B.J., 2007. A genome-wide transgenic RNAi library for conditional gene inactivation in Drosophila. Nature 448, 151-156. https://doi.org/10.1038/nature05954

Dionne, H., Hibbard, K.L., Cavallaro, A., Kao, J., Rubin, G.M., 2018. Genetic Reagents for Making SplitGAL4 Lines in Drosophila. Genetics 209, 31-35. https://doi.org/10.1534/genetics.118.300682

Dolan, M.-J., Luan, H., Shropshire, W.C., Sutcliffe, B., Cocanougher, B., Scott, R.L., Frechter, S., Zlatic, M., Jefferis, G.S.X.E., White, B.H., 2017. Facilitating Neuron-Specific Genetic Manipulations in Drosophila melanogaster using a split Gal4 repressor. Genetics 206, 775-784. https://doi.org/10.1534/genetics.116.199687/-/DC1.1

Dow, L.E., Fisher, J., O’Rourke, K.P., Muley, A., Kastenhuber, E.R., Livshits, G., Tschaharganeh, D.F., Socci, N.D., Lowe, S.W., 2015. Inducible in vivo genome editing with CRISPR-Cas9. Nat. Biotechnol. 33, 390-394. https://doi.org/10.1038/nbt.3155

Duan, J., Xu, H., Ma, S., Guo, H., Wang, F., Zhao, P., Xia, Q., 2013. Cre-mediated targeted gene activation in the middle silk glands of transgenic silkworms (Bombyx mori). Transgenic Res. 22, 607-619. https://doi.org/10.1007/s11248-012-9677-0

Duffy, J.B., 2002. GAL4 System in Drosophila: A Fly Geneticist's Swiss Army Knife. Genesis 34, 1-15. https://doi.org/10.1002/gene.10150

Faden, F., Ramezani, T., Mielke, S., Almudi, I., Nairz, K., Froehlich, M.S., Höckendorff, J., Brandt, W., Hoehenwarter, W., Dohmen, R.J., Schnittger, A., Dissmeyer, N., 2016. Phenotypes on demand via switchable target protein degradation in multicellular organisms. Nat. Commun. 7, 12202. https://doi.org/10.1038/ncomms12202

Feil, R., Wagner, J., Metzger, D., Chambon, P., 1997. Regulation of Cre Recombinase Activity by Mutated Estrogen Receptor Ligand-Binding Domains. Biochem. Biophys. Res. Commun. 237, 752-757. https://doi.org/10.1006/bbrc.1997.7124

Felletti, M., Hartig, J.S., 2017. Ligand-dependent ribozymes. Wiley Interdiscip. Rev. RNA 8, e1395. https://doi.org/10.1002/wrna.1395

Fielmich, L.-E., Schmidt, R., Dickinson, D.J., Goldstein, B., Akhmanova, A., van den Heuvel, S., 2018. Optogenetic dissection of mitotic spindle positioning in vivo. Elife 7, e38198. https://doi.org/10.7554/eLife.38198

Fisher, Y.E., Yang, H.H., Isaacman-beck, J., Xie, M., Gohl, D.M., Clandinin, T.R., 2017. FlpStop, a tool for conditional gene control in Drosophila. Elife 6, 1-33. https://doi.org/10.7554/eLife.22279

Flavell, S.W., Pokala, N., Macosko, E.Z., Albrecht, D.R., Larsch, J., Bargmann, C.I., 2013. Serotonin and the Neuropeptide PDF Initiate and Extend Opposing Behavioral States in C. elegans. Cell 154, 10231035. https://doi.org/10.1016/j.cell.2013.08.001

Ford, D., Hoe, N., Landis, G., Tozer, K., Luu, A., Bhole, D., Badrinath, A., Tower, J., 2007. Alteration of Drosophila life span using conditional, tissue-specific expression of transgenes triggered by doxycyline or RU486/Mifepristone. Exp. Gerontol. 42, 483-497. https://doi.org/10.1016/j.exger.2007.01.004 
Fortin, P.-Y., Genevois, C., Chapolard, M., Santalucía, T., Planas, A.M., Couillaud, F., 2014. Dual-reporter in vivo imaging of transient and inducible heat-shock promoter activation. Biomed. Opt. Express 5, 457. https://doi.org/10.1364/BOE.5.000457

Frickenhaus, M., Wagner, M., Mallik, M., Catinozzi, M., Storkebaum, E., 2015. Highly efficient cell-typespecific gene inactivation reveals a key function for the Drosophila FUS homolog cabeza in neurons. Sci. Rep. 5, 1-10. https://doi.org/10.1038/srep09107

Germani, F., Bergantinos, C., Johnston, L.A., 2018. Mosaic Analysis in Drosophila. Genetics 208, 473-490. https://doi.org/10.1534/genetics.117.300256

Ghosh, D., Seydoux, G., 2008. Inhibition of Transcription by the Caenorhabditis elegans Germline Protein PIE-1: Genetic Evidence for Distinct Mechanisms Targeting Initiation and Elongation. Genetics 178, 235-243. https://doi.org/10.1534/genetics.107.083212

Giles, N.H., Geever, R.F., Asch, D.K., Avalos, J., Case, M.E., 1991. Organization and Regulation of the Qa (Quinic Acid) Genes in Neurospora crassa and Other Fungi. J. Hered. 82, 1-7. https://doi.org/10.1093/jhered/82.1.1

Gohl, D.M., Silies, M.A., Gao, X.J., Bhalerao, S., Luongo, F.J., Lin, C., Potter, C.J., Clandinin, T.R., 2011. A versatile in vivo system for directed dissection of gene expression patterns. Nat. Methods 8, 231241. https://doi.org/10.1038/nmeth.1561

Golic, K.G., Lindquist, S., 1989. The FLP Recombinase of Yeast Catalyzes Site-Specific Recombination in the Drosophila Genome. Cell 59, 499-509. https://doi.org/10.1016/0092-8674(89)90033-0

Gossen, M., Bujard, H., 1992. Tight control of gene expression in mammalian cells by tetracyclineresponsive promoters. Proc. Natl. Acad. Sci. 89, 5547-5551. https://doi.org/10.1073/pnas.89.12.5547

Gossen, M., Freundlieb, S., Bender, G., Muller, G., Hillen, W., Bujard, H., 1995. Transcriptional activation by tetracyclines in mammalian cells. Science $268,1766-1769$. https://doi.org/10.1126/science. 7792603

Groth, A.C., 2004. Construction of Transgenic Drosophila by Using the Site-Specific Integrase From Phage C31. Genetics 166, 1775-1782. https://doi.org/10.1534/genetics.166.4.1775

Haghighat-Khah, R.E., Scaife, S., Martins, S., St John, O., Matzen, K.J., Morrison, N., Alphey, L., 2015. SiteSpecific Cassette Exchange Systems in the Aedes aegypti Mosquito and the Plutella xylostella Moth. PLoS One 10, e0121097. https://doi.org/10.1371/journal.pone.0121097

Halfon, M.S., Kose, H., Chiba, A., Keshishian, H., 1997. Targeted gene expression without a tissue-specific promoter: Creating mosaic embryos using laser-induced single-cell heat shock. Proc. Natl. Acad. Sci. 94, 6255-6260. https://doi.org/10.1073/pnas.94.12.6255

Hara, K., Kuwayama, H., Inukai, Y., 2009. A novel fusion protein that functions as an enhanced green fluorescent protein reporter and a tetracycline-controlled transcriptional activator. Dev. Genes Evol. 219, 103-110. https://doi.org/10.1007/s00427-009-0274-z

Hara, K., Kuwayama, H., Yaginuma, T., Niimi, T., 2008. Establishment of a Tetracycline-Off System using a piggyBac-based Vector as a Gene Functional Analysis Tool for the Temporal Targeting of Gene Expression. J. Insect Biotechnol. Sericology 77, 159-166. https://doi.org/https://doi.org/10.11416/jibs.77.3_159 
Harmansa, S., Hamaratoglu, F., Affolter, M., Caussinus, E., 2015. Dpp spreading is required for medial but not for lateral wing disc growth. Nature 527, 317-322. https://doi.org/10.1038/nature15712

Hayashi, S., Ito, K., Sado, Y., Taniguchi, M., Akimoto, A., Takeuchi, H., Aigaki, T., Matsuzaki, F., Nakagoshi, H., Tanimura, T., Ueda, R., Uemura, T., Yoshihara, M., Goto, S., 2002. GETDB, a Database Compiling Expression Patterns and Molecular Locations of a Collection of Gal4 Enhancer Traps. Genesis 34, 58-61. https://doi.org/10.1002/gene.10137

Heidmann, D., Lehner, C.F., 2001. Reduction of Cre recombinase toxicity in proliferating Drosophila cells by estrogen-dependent activity regulation. Dev. Genes Evol. 211, 458-465. https://doi.org/10.1007/s004270100167

Heitzler, P., Simpson, P., 1991. The choice of cell fate in the epidermis of Drosophila. Cell 64, 1083-1092. https://doi.org/10.1016/0092-8674(91)90263-X

Hercus, M.J., Loeschcke, V., Rattan, S.I.S., 2003. Lifespan extension of Drosophila melanogaster through hormesis by repeated mild heat stress. Biogerontology 4, 149-56. https://doi.org/10.1023/a:1024197806855

Hermann, A., Liewald, J.F., Gottschalk, A., 2015. A photosensitive degron enables acute light-induced protein degradation in the nervous system. Curr. Biol. 25, R749-R750. https://doi.org/10.1016/j.cub.2015.07.040

Hill, A.J., Mansfield, R., Lopez, J.M.N.G., Raizen, D.M., Van Buskirk, C., 2014. Cellular Stress Induces a Protective Sleep-like State in C. elegans. Curr. Biol. 24, 2399-2405. https://doi.org/10.1016/j.cub.2014.08.040

Hoier, E.F., Mohler, W.A., Kim, S.K., Hajnal, A., 2000. The Caenorhabditis elegans APC-related gene apr-1 is required for epithelial cell migration and Hox gene expression. Genes Dev. 14, 874-886. https://doi.org/10.5167/uzh-744

Hörner, M., Müller, K., Weber, W., 2017. Light-Responsive Promoters, in: Gould, D. (Ed.), Mammalian Synthetic Promoters. Humana, New York, NY, pp. 173-186. https://doi.org/10.1007/978-1-49397223-4_13

Hubbard, E.J.A., 2014. FLP/FRT and Cre/lox recombination technology in C. elegans. Methods 68, 417424. https://doi.org/10.1016/j.ymeth.2014.05.007

Huiet, L., Giles, N.H., 1986. The qa repressor gene of Neurospora crassa: wild-type and mutant nucleotide sequences. Proc. Natl. Acad. Sci. 83, 3381-3385.

https://doi.org/10.1073/pnas.83.10.3381

Huynh, N., Zeng, J., Liu, W., King-Jones, K., 2018. A Drosophila CRISPR/Cas9 Toolkit for Conditionally Manipulating Gene Expression in the Prothoracic Gland as a Test Case for Polytene Tissues. G3 (Bethesda) 8, 3593-3605. https://doi.org/10.1534/g3.118.200539

Imamura, M., Nakai, J., Inoue, S., Quan, G.X., Kanda, T., Tamura, T., 2003. Targeted Gene Expression Using the GAL4/UAS System in the Silkworm Bombyx mori. Genetics 165, 1329-1340.

Jain, P.K., Ramanan, V., Schepers, A.G., Dalvie, N.S., Panda, A., Fleming, H.E., Bhatia, S.N., 2016. Development of Light-Activated CRISPR Using Guide RNAs with Photocleavable Protectors. Angew. Chemie Int. Ed. 55, 12440-12444. https://doi.org/10.1002/anie.201606123 
Jenett, A., Rubin, G.M., Ngo, T.B., Shepherd, D., Murphy, C., Dionne, H., Pfeiffer, B.D., Cavallaro, A., Hall, D., Jeter, J., lyer, N., Fetter, D., Hausenfluck, J.H., Peng, H., Trautman, E.T., Svirskas, R.R., Myers, E.W., Iwinski, Z.R., Aso, Y., Depasquale, G.M., Enos, A., Hulamm, P., Chun, S., Lam, B., Li, H., Laverty, T.R., Long, F., Qu, L., Murphy, S.D., Rokicki, K., Safford, T., Shaw, K., Simpson, J.H., Sowell, A., Tae, S., Yu, Y., Zugates, C.T., 2012. Resource A GAL4-Driver Line Resource for Drosophila Neurobiology. CellReports 2, 991-1001. https://doi.org/10.1016/j.celrep.2012.09.011

Jia, Y., Xu, R.-G., Ren, X., Ewen-Campen, B., Rajakumar, R., Zirin, J., Yang-Zhou, D., Zhu, R., Wang, F., Mao, D., Peng, P., Qiao, H.-H., Wang, X., Liu, L.-P., Xu, B., Ji, J.-Y., Liu, Q., Sun, J., Perrimon, N., Ni, J.Q., 2018. Next-generation CRISPR/Cas9 transcriptional activation in Drosophila using flySAM. Proc. Natl. Acad. Sci. 115, 4719-4724. https://doi.org/10.1073/pnas.1800677115

Kaczmarczyk, S.J., 2001. A single vector containing modified cre recombinase and LOX recombination sequences for inducible tissue-specific amplification of gene expression. Nucleic Acids Res. 29, e56. https://doi.org/10.1093/nar/29.12.e56

Kage-Nakadai, E., Imae, R., Suehiro, Y., Yoshina, S., Hori, S., Mitani, S., 2014. A Conditional Knockout Toolkit for Caenorhabditis elegans Based on the Cre/loxP Recombination. PLoS One 9, e114680. https://doi.org/10.1371/journal.pone.0114680

Kakidani, H., Ptashne, M., 1988. GAL4 activates gene expression in mammalian cells. Cell 52, 161-167. https://doi.org/10.1016/0092-8674(88)90504-1

Kallunki, T., Barisic, M., Jäättelä, M., Liu, B., 2019. How to Choose the Right Inducible Gene Expression System for Mammalian Studies? Cells 8, 796. https://doi.org/10.3390/cells8080796

Karasaki, N., Mon, H., Takahashi, M., Lee, J.M., Koga, K., Kawaguchi, Y., Kusakabe, T., 2009. Establishment of tetracycline-inducible gene expression systems in the silkworm, Bombyx mori. Biotechnol. Lett. 31, 495-500. https://doi.org/10.1007/s10529-008-9898-8

Kawaguchi, A., Utsumi, N., Morita, M., Ohya, A., Wada, S., 2015. Application of the cis-regulatory region of a heat-shock protein 70 gene to heat-inducible gene expression in the ascidian Ciona intestinalis. Genesis 53, 170-182. https://doi.org/10.1002/dvg.22834

Kennerdell, J.R., Carthew, R.W., 2000. Heritable gene silencing in Drosophila using double-stranded RNA. Nat. Biotechnol. 18, 896-898. https://doi.org/10.1038/78531

Kerk, S.Y., Kratsios, P., Hart, M., Mourao, R., Hobert, O., 2017. Diversification of C. elegans Motor Neuron Identity via Selective Effector Gene Repression. Neuron 93, 80-98. https://doi.org/10.1016/j.neuron.2016.11.036

Kim, J.C., Cook, M.N., Carey, M.R., Shen, C., Regehr, W.G., Dymecki, S.M., 2009. Linking Genetically Defined Neurons to Behavior through a Broadly Applicable Silencing Allele. Neuron 63, 305-315. https://doi.org/10.1016/j.neuron.2009.07.010

Knapp, J.-M., Chung, P., Simpson, J.H., 2015. Generating Customized Transgene Landing Sites and MultiTransgene Arrays in Drosophila Using phiC31 Integrase. Genetics 199, 919-934. https://doi.org/10.1534/genetics.114.173187

Kokoza, V.A., Raikhel, A.S., 2011. Targeted gene expression in the transgenic Aedes aegypti using the binary Gal4-UAS system. Insect Biochem. Mol. Biol. 41, 637-644. https://doi.org/10.1016/j.ibmb.2011.04.004 
Konermann, S., Brigham, M.D., Trevino, A.E., Hsu, P.D., Heidenreich, M., Le Cong, Platt, R.J., Scott, D.A., Church, G.M., Zhang, F., 2013. Optical control of mammalian endogenous transcription and epigenetic states. Nature 500, 472-476. https://doi.org/10.1038/nature12466

Kuhlman, S.J., Huang, Z.J., 2008. High-Resolution Labeling and Functional Manipulation of Specific Neuron Types in Mouse Brain by Cre-Activated Viral Gene Expression. PLoS One 3, e2005. https://doi.org/10.1371/journal.pone.0002005

Labbé, G.M.C., Nimmo, D.D., Alphey, L., 2010. piggybac- and PhiC31-Mediated Genetic Transformation of the Asian Tiger Mosquito, Aedes albopictus (Skuse). PLoS Negl. Trop. Dis. 4, e788. https://doi.org/10.1371/journal.pntd.0000788

Lai, S.L., Lee, T., 2006. Genetic mosaic with dual binary transcriptional systems in Drosophila. Nat. Neurosci. 9, 703-709. https://doi.org/10.1038/nn1681

Lewandoski, M., 2001. Conditional control of gene expression in the mouse. Nat. Rev. Genet. 2, 743755. https://doi.org/10.1038/35093537

Lin, C.-C., Potter, C.J., 2016. Editing Transgenic DNA Components by Inducible Gene Replacement in Drosophila melanogaster. Genetics 203, 1613-1628. https://doi.org/10.1534/genetics.116.191783

Lin, J.Y., Sann, S.B., Zhou, K., Nabavi, S., Proulx, C.D., Malinow, R., Jin, Y., Tsien, R.Y., 2013. Optogenetic Inhibition of Synaptic Release with Chromophore-Assisted Light Inactivation (CALI). Neuron 79, 241-253. https://doi.org/10.1016/j.neuron.2013.05.022

Lin, S., Ewen-Campen, B., Ni, X., Housden, B.E., Perrimon, N., 2015. In Vivo Transcriptional Activation Using CRISPR/Cas9 in Drosophila. Genetics 201, 433-442. https://doi.org/10.1534/genetics.115.181065

Lis, J.T., Simon, J.A., Sutton, C.A., 1983. New heat shock puffs and $\beta$-galactosidase activity resulting from transformation of Drosophila with an hsp70-lacZ hybrid gene. Cell 35, 403-410. https://doi.org/10.1016/0092-8674(83)90173-3

Lithgow, G.J., White, T.M., Hinerfeld, D.A., Johnson, T.E., 1994. Thermotolerance of a Long-lived Mutant of Caenorhabditis elegans. J. Gerontol. 49, B270-B276. https://doi.org/10.1093/geronj/49.6.B270

Liu, P., Long, L., Xiong, K., Yu, B., Chang, N., Xiong, J.-W., Zhu, Z., Liu, D., 2014. Heritable/conditional genome editing in C. elegans using a CRISPR-Cas9 feeding system. Cell Res. 24, 886-889. https://doi.org/10.1038/cr.2014.73

Lo, T., Pickle, C.S., Lin, S., Ralston, E.J., Gurling, M., Schartner, C.M., Bian, Q., Doudna, J.A., Meyer, B.J., 2013. Precise and Heritable Genome Editing in Evolutionarily Diverse Nematodes Using TALENs and CRISPR/Cas9 to Engineer Insertions and Deletions. Genetics 195, 331-348. https://doi.org/10.1534/genetics.113.155382

Long, D., Zhao, A., Chen, X., Zhang, Y., Lu, W., Guo, Q., Handler, A.M., Xiang, Z., 2012. FLP RecombinaseMediated Site-Specific Recombination in Silkworm, Bombyx mori. PLoS One 7, e40150. https://doi.org/10.1371/journal.pone.0040150

Luan, H., Peabody, N.C., Vinson, C.R., White, B.H., 2006. Refined Spatial Manipulation of Neurotechnique Neuronal Function by Combinatorial Restriction of Transgene Expression. Neuron 52, 425-436. https://doi.org/10.1016/j.neuron.2006.08.028 
1002

1003

1004

1005

1006

1007

1008

1009

1010

1011

1012

1013

1014

1015

1016

1017

1018

1019

1020

1021

1022

1023

1024

1025

1026

1027

1028

1029

1030

1031

1032

1033

1034

1035

1036

1037

1038

1039

1040

Luo, J., Shen, P., Chen, J., 2019. A modular toolset of phiC31-based fluorescent protein tagging vectors for Drosophila. Fly (Austin). 13, 29-41. https://doi.org/10.1080/19336934.2019.1595999

Lycett, G.J., Kafatos, F.C., Loukeris, T.G., 2004. Conditional Expression in the Malaria Mosquito Anopheles stephensi With Tet-On and Tet-Off Systems. Genetics 167, 1781-1790. https://doi.org/10.1534/genetics.104.028175

Lynd, A., Lycett, G.J., 2012. Development of the Bi-Partite Gal4-UAS System in the African Malaria Mosquito, Anopheles gambiae. PLoS One 7. https://doi.org/10.1371/journal.pone.0031552

Macosko, E.Z., Pokala, N., Feinberg, E.H., Chalasani, S.H., Butcher, R.A., Clardy, J., Bargmann, C.I., 2009. A hub-and-spoke circuit drives pheromone attraction and social behaviour in $C$. elegans. Nature 458, 1171-1176. https://doi.org/10.1038/nature07886

Maltzman, J.S., Turka, L.A., 2007. Conditional Gene Expression: A New Tool for the Transplantologist. Am. J. Transplant. 7, 733-740. https://doi.org/10.1111/j.1600-6143.2006.01685.x

Manivannan, S.N., Pandey, P., Nagarkar-jaiswal, S., 2019. Flip-flop Mediated Conditional Gene Inactivation in Drosophila. Bio-protocol 9, 1-17. https://doi.org/10.21769/BioProtoc.3157.Flip-flop

Mann, K., Gordon, M.D., Scott, K., 2013. A pair of interneurons influences the choice between feeding and locomotion in Drosophila. Neuron 79, 754-765. https://doi.org/10.1016/j.neuron.2013.06.018

Mao, C., Wikramanayake, A.H., Gan, L., Chuang, C., Summers, R.G., Klein, W.H., 1996. Altering cell fates in sea urchin embryos by overexpressing SpOtx, an orthodenticle-related protein. Development 122, 1489-1498.

Mao, S., Qi, Y., Zhu, H., Huang, X., Zou, Y., Chi, T., 2019. A Tet/Q Hybrid System for Robust and Versatile Control of Transgene Expression in C. elegans. iScience 11, 224-237. https://doi.org/10.1016/j.isci.2018.12.023

Matthews, B.J., Younger, M.A., Vosshall, L.B., 2019. The ion channel ppk301 controls freshwater egglaying in the mosquito Aedes aegypti. Elife 8, e43963. https://doi.org/10.7554/eLife.43963

McGuire, S.E., Le, P.T., Osborn, A.J., Matsumoto, K., Davis, R.L., 2003. Spatiotemporal Rescue of Memory Dysfunction in Drosophila. Science 302, 1765-1768. https://doi.org/10.1126/science.1089035

McLeod, M., Craft, S., Broach, J.R., 1986. Identification of the crossover site during FLP-mediated recombination in the Saccharomyces cerevisiae plasmid 2 microns circle. Mol. Cell. Biol. 6, 33573367. https://doi.org/10.1128/MCB.6.10.3357

McMahon, A.P., Novak, T.J., Britten, R.J., Davidson, E.H., 1984. Inducible expression of a cloned heat shock fusion gene in sea urchin embryos. Proc. Natl. Acad. Sci. U. S. A. 81, 7490-7494. https://doi.org/10.1073/pnas.81.23.7490

Meredith, J.M., Basu, S., Nimmo, D.D., Larget-Thiery, I., Warr, E.L., Underhill, A., McArthur, C.C., Carter, V., Hurd, H., Bourgouin, C., Eggleston, P., 2011. Site-Specific Integration and Expression of an AntiMalarial Gene in Transgenic Anopheles gambiae Significantly Reduces Plasmodium Infections. PLoS One 6, e14587. https://doi.org/10.1371/journal.pone.0014587

Mondal, K., Dastidar, A.G., Singh, G., Madhusudhanan, S., Gande, S.L., VijayRaghavan, K., Varadarajan, R., 2007. Design and Isolation of Temperature-sensitive Mutants of Gal4 in Yeast and Drosophila. J. Mol. Biol. 370, 939-950. https://doi.org/10.1016/j.jmb.2007.05.035 
1041

1042

1043

1044

1045

1046

1047

1048

1049

1050

1051

1052

1053

1054

1055

1056

1057

1058

1059

1060

1061

1062

1063

1064

1065

1066

1067

1068

1069

1070

1071

1072

1073

1074

1075

1076

1077

1078

1079

Monsalve, G.C., Yamamoto, K.R., Ward, J.D., 2019. A New Tool for Inducible Gene Expression in Caenorhabditis elegans. Genetics 211, 419-430. https://doi.org/10.1534/genetics.118.301705

Morris, A.C., Schaub, T.L., James, A.A., 1991. FLP-mediated recombination in the vector mosquite, Aedes aegypti. Nucleic Acids Res. 19, 5895-5900. https://doi.org/10.1093/nar/19.21.5895

Müller, K., Engesser, R., Schulz, S., Steinberg, T., Tomakidi, P., Weber, C.C., Ulm, R., Timmer, J., Zurbriggen, M.D., Weber, W., 2013. Multi-chromatic control of mammalian gene expression and signaling. Nucleic Acids Res. 41, e124-e124. https://doi.org/10.1093/nar/gkt340

Müller, K., Zurbriggen, M.D., Weber, W., 2014. Control of gene expression using a red- and far-red lightresponsive bi-stable toggle switch. Nat. Protoc. 9, 622-632.

https://doi.org/10.1038/nprot.2014.038

Muñoz-jiménez, C., Ayuso, C., Dobrzynska, A., Torres-Mendéz, A., de la Cruz Ruiz, P., Askjaer, P., 2017. An Efficient FLP-Based Toolkit for Spatiotemporal Control of Gene Expression in Caenorhabditis elegans. Genetics 206, 1763-1778. https://doi.org/10.1534/genetics.117.201012/-/DC1.1

Nance, J., Frøkjær-Jensen, C., 2019. The Caenorhabditis elegans Transgenic Toolbox. Genetics 212, 959990. https://doi.org/10.1534/genetics.119.301506

Nern, A., Pfeiffer, B.D., Svoboda, K., Rubin, G.M., 2011. Multiple new site-specific recombinases for use in manipulating animal genomes. Proc. Natl. Acad. Sci. 108, 14198-14203.

https://doi.org/10.1073/pnas.1111704108

Newsome, T.P., Åsling, B., Dickson, B.J., 2000. Analysis of Drosophila photoreceptor axon guidance in eye-specific mosaics. Development 127, 851-860.

Ni, J.-Q., Zhou, R., Czech, B., Liu, L.-P., Holderbaum, L., Yang-Zhou, D., Shim, H.-S., Tao, R., Handler, D., Karpowicz, P., Binari, R., Booker, M., Brennecke, J., Perkins, L.A., Hannon, G.J., Perrimon, N., 2011. A genome-scale shRNA resource for transgenic RNAi in Drosophila. Nat. Methods 8, 405-407. https://doi.org/10.1038/nmeth.1592

Nihongaki, Y., Yamamoto, S., Kawano, F., Suzuki, H., Sato, M., 2015. CRISPR-Cas9-based Photoactivatable Transcription System. Chem. Biol. 22, 169-174. https://doi.org/10.1016/j.chembiol.2014.12.011

Nikitina, E.A., Kaminskaya, A.N., Molotkov, D.A., Popov, A. V, Savvateeva-Popova, E. V, 2014. Effect of heat shock on courtship behavior, sound production, and learning in comparison with the brain content of LIMK1 in Drosophila melanogaster males with altered structure of the limk1 gene. J. Evol. Biochem. Physiol. 50, 154-166. https://doi.org/10.1134/S0022093014020082

Nimmo, D.D., Alphey, L., Meredith, J.M., Eggleston, P., 2006. High efficiency site-specific genetic engineering of the mosquito genome. Insect Mol. Biol. 15, 129-136. https://doi.org/10.1111/j.1365-2583.2006.00615.x

Nonet, M.L., 2020. Efficient Transgenesis in Caenorhabditis elegans Using Flp Recombinase-Mediated Cassette Exchange. Genetics 215, 903-921. https://doi.org/10.1534/genetics.120.303388

Osterwalder, T., Yoon, K.S., White, B.H., Keshishian, H., 2001. A conditional tissue-specific transgene expression system using inducible GAL4. Proc. Natl. Acad. Sci. 98, 12596-12601. https://doi.org/10.1073/pnas.221303298

Pani, A.M., Goldstein, B., 2018. Direct visualization of a native Wnt in vivo reveals that a long-range Wnt 

gradient forms by extracellular dispersal. Elife 7, e38325. https://doi.org/10.7554/eLife.38325

Patel, T., Hobert, O., 2017. Coordinated control of terminal differentiation and restriction of cellular plasticity. Elife 6, e24100. https://doi.org/10.7554/eLife.24100

Patel, V.B., Schweizer, M., Dykstra, C.C., Kushner, S.R., Giles, N.H., 1981. Genetic organization and transcriptional regulation in the qa gene cluster of Neurospora crassa. Proc. Natl. Acad. Sci. 78, 5783-5787. https://doi.org/10.1073/pnas.78.9.5783

Pérez-Garijo, A., Fuchs, Y., Steller, H., 2013. Apoptotic cells can induce non-autonomous apoptosis through the TNF pathway. Elife 2013, e01004. https://doi.org/10.7554/eLife.01004

Pfeiffer, B.D., Ngo, T.B., Hibbard, K.L., Murphy, C., Jenett, A., Truman, J.W., Rubin, G.M., 2010. Refinement of Tools for Targeted Gene Expression in Drosophila. Genetics 186, 735-755. https://doi.org/10.1534/genetics.110.119917

Poirier, L., Shane, A., Zheng, J., Seroude, L., 2008. Characterization of the Drosophila Gene-Switch system in aging studies: a cautionary tale. Aging Cell 7, 758-770. https://doi.org/10.1111/j.14749726.2008.00421.x

Polstein, L.R., Gersbach, C.A., 2015. A light-inducible CRISPR-Cas9 system for control of endogenous gene activation. Nat. Chem. Biol. 11, 198-200. https://doi.org/10.1038/nchembio.1753

Polstein, L.R., Gersbach, C.A., 2012. Light-Inducible Spatiotemporal Control of Gene Activation by Customizable Zinc Finger Transcription Factors. J. Am. Chem. Soc. 134, 16480-16483. https://doi.org/10.1021/ja3065667

Port, F., Bullock, S.L., 2016. Augmenting CRISPR applications in Drosophila with tRNA-flanked sgRNAs. Nat. Methods 13, 852-854. https://doi.org/10.1038/nmeth.3972

Port, F., Starostecka, M., Boutros, M., 2020a. Multiplexed conditional genome editing with Cas12a in Drosophila. Proc. Natl. Acad. Sci. 117, 22890-22899. https://doi.org/10.1073/pnas.2004655117

Port, F., Strein, C., Stricker, M., Rauscher, B., Heigwer, F., Zhou, J., Beyersdörffer, C., Frei, J., Hess, A., Kern, K., Lange, L., Langner, N., Malamud, R., Pavlović, B., Rädecke, K., Schmitt, L., Voos, L., Valentini, E., Boutros, M., 2020b. A large-scale resource for tissue-specific CRISPR mutagenesis in Drosophila. Elife 9, e53865. https://doi.org/10.7554/eLife.53865

Potter, C.J., Luo, L., 2011. Using the Q system in Drosophila melanogaster. Nat. Protoc. 6, 1105-1120. https://doi.org/10.1038/nprot.2011.347

Potter, C.J., Tasic, B., Russler, E. V., Liang, L., Luo, L., 2010. The Q System: A Repressible Binary System for Transgene Expression, Lineage Tracing, and Mosaic Analysis. Cell 141, 536-548. https://doi.org/10.1016/j.cell.2010.02.025

Riabinina, O., Luginbuhl, D., Marr, E., Liu, S., Wu, M.N., Luo, L., Potter, C.J., 2015. Improved and expanded Q-system reagents for genetic manipulations. Nat. Methods 12, 219-222. https://doi.org/10.1038/nmeth.3250

Riabinina, O., Potter, C.J., 2016. The Q-System: A Versatile Expression System for Drosophila, in: Walker, J.M. (Ed.), Methods in Molecular Biology. Springer Nature Switzerland, Heidelberg, pp. 53-78. https://doi.org/10.1007/978-1-4939-6371-3_3

Riabinina, O., Task, D., Marr, E., Lin, C.-C., Alford, R., O’Brochta, D.A., Potter, C.J., 2016. Organization of 
olfactory centres in the malaria mosquito Anopheles gambiae. Nat. Commun. 7, 13010. https://doi.org/10.1038/ncomms13010

Riabinina, O., Vernon, S.W., Dickson, B.J., Baines, R.A., 2019. Split-QF System for Fine-Tuned Transgene Expression in Drosophila. Genetics 212, 53-63. https://doi.org/10.1534/genetics.119.302034

Ritossa, F., 1962. A new puffing pattern induced by temperature shock and DNP in Drosophila. Experientia 18, 571-573. https://doi.org/10.1007/BF02172188

Roman, G., Endo, K., Zong, L., Davis, R.L., 2001. P\{Switch\}, a system for spatial and temporal control of gene expression in Drosophila melanogaster. Proc. Natl. Acad. Sci. 98, 12602-12607. https://doi.org/10.1073/pnas.221303998

Sauer, B., 1987. Functional Expression of the cre-lox Site-Specific Recombination System in the Yeast Saccharomyces cerevisiae. Mol. Cell. Biol. 7, 2087-2096. https://doi.org/10.1128/MCB.7.6.2087

Sauer, B., Henderson, N., 1988. Site-specific DNA recombination in mammalian cells by the Cre recombinase of bacteriophage P1. PNAS 85, 5166-5170. https://doi.org/10.1073/pnas.85.14.5166

Schetelig, M.F., Handler, A.M., 2013. A Functional Comparison of the 3xP3 Promoter by RecombinaseMediated Cassette Exchange in Drosophila and a Tephritid Fly, Anastrepha suspensa. G3 (Bethesda) 3, 687-693. https://doi.org/10.1534/g3.112.005488

Schinko, J.B., Weber, M., Viktorinova, I., Kiupakis, A., Averof, M., Klingler, M., Wimmer, E.A., Bucher, G., 2010. Functionality of the GAL4/UAS system in Tribolium requires the use of endogenous core promoters. BMC Dev. Biol. 10, 53. https://doi.org/10.1186/1471-213X-10-53

Schmidt-Supprian, M., Rajewsky, K., 2007. Vagaries of conditional gene targeting. Nat. Immunol. 8, 665668. https://doi.org/10.1038/ni0707-665

Schnütgen, F., Doerflinger, N., Calléja, C., Wendling, O., Chambon, P., Ghyselinck, N.B., 2003. A directional strategy for monitoring Cre-mediated recombination at the cellular level in the mouse. Nat. Biotechnol. 21, 562-565. https://doi.org/10.1038/nbt811

Scialo, F., Sriram, A., Stefanatos, R., Sanz, A., 2016. Practical Recommendations for the Use of the GeneSwitch Gal4 System to Knock-Down Genes in Drosophila melanogaster. PLoS One 11, e0161817. https://doi.org/10.1371/journal.pone.0161817

Sethi, S., Wang, J.W., 2017. A versatile genetic tool for post-translational control of gene expression in Drosophila melanogaster. Elife 6, e30327. https://doi.org/10.7554/eLife.30327

Shen, Z., Zhang, X., Chai, Y., Zhu, Z., Yi, P., Feng, G., Li, W., Ou, G., 2014. Conditional Knockouts Generated by Engineered CRISPR-Cas9 Endonuclease Reveal the Roles of Coronin in C. elegans Neural Development. Dev. Cell 30, 625-636. https://doi.org/10.1016/j.devcel.2014.07.017

Shimizu-Sato, S., Huq, E., Tepperman, J.M., Quail, P.H., 2002. A light-switchable gene promoter system. Nat. Biotechnol. 20, 1041-1044. https://doi.org/10.1038/nbt734

Siegal, M.L., Hartl, D.L., 1996. Transgene Coplacement and High Efficiency Site-Specific Recombination with the Cre/loxP System in Drosophila. Genetics 144, 715-726.

Silies, M., Gohl, D.M., Fisher, Y.E., Freifeld, L., Clark, D.A., Clandinin, T.R., 2013. Modular Use of Peripheral Input Channels Tunes Motion-Detecting Circuitry. Neuron 79, 111-127. https://doi.org/10.1016/j.neuron.2013.04.029 
Silver, K., Jiang, H., Fu, J., Phillips, T.W., Beeman, R.W., Park, Y., 2015. The Tribolium castaneum cell line TcA: a new tool kit for cell biology. Sci. Rep. 4, 6840. https://doi.org/10.1038/srep06840

Stebbins, M.J., Urlinger, S., Byrne, G., Bello, B., Hillen, W., Yin, J.C.P., 2001. Tetracycline-inducible systems for Drosophila. Proc. Natl. Acad. Sci. 98, 10775-10780. https://doi.org/10.1073/pnas.121186498

Stebbins, M.J., Yin, J.C.., 2001. Adaptable doxycycline-regulated gene expression systems for Drosophila. Gene 270, 103-111. https://doi.org/10.1016/S0378-1119(01)00447-4

Steller, H., Pirrotta, V., 1985. Expression of the Drosophila white gene under the control of the hsp70 heat shock promoter. EMBO J. 4, 3765-3772. https://doi.org/10.1002/j.1460-2075.1985.tb04146.x

Sternberg, N., 1981. Bacteriophage P1 site-specific recombination. J. Mol. Biol. 150, 603-608. https://doi.org/10.1016/0022-2836(81)90384-3

Stringham, E.G., Candido, E.P.M., 1993. Targeted single-cell induction of gene products in Caenorhabditis elegans: A new tool for developmental studies. J. Exp. Zool. 266, 227-233. https://doi.org/10.1002/jez.1402660309

Stringham, E.G., Dixon, D.K., Jones, D., Candido, E.P.M., 1992. Temporal and spatial expression patterns of the small heat shock (hsp16) genes in transgenic Caenorhabditis elegans. Mol. Biol. Cell 3, 221233. https://doi.org/10.1091/mbc.3.2.221

Struhl, G., Basler, K., 1993. Organizing activity of wingless protein in Drosophila. Cell 72, 527-540. https://doi.org/10.1016/0092-8674(93)90072-X

Suster, M.L., Seugnet, L., Bate, M., Sokolowski, M.B., 2004. Refining GAL4-driven transgene expression in Drosophila with a GAL80 enhancer-trap. Genesis 39, 240-245. https://doi.org/10.1002/gene.20051

Sweeney, S.T., Broadie, K., Keane, J., Niemann, H., O'Kane, C.J., 1995. Targeted expression of tetanus toxin light chain in Drosophila specifically eliminates synaptic transmission and causes behavioral defects. Neuron 14, 341-351. https://doi.org/10.1016/0896-6273(95)90290-2

Szuts, D., Bienz, M., 2000. LexA chimeras reveal the function of Drosophila Fos as a context-dependent transcriptional activator. Proc. Natl. Acad. Sci. 97, 5351-5356. https://doi.org/10.1073/pnas.97.10.5351

Tang, W., Hu, J.H., Liu, D.R., 2017. Aptazyme-embedded guide RNAs enable ligand-responsive genome editing and transcriptional activation. Nat. Commun. 8, 15939. https://doi.org/10.1038/ncomms15939

Tatsuke, T., Lee, J.M., 2013. Tightly controlled tetracycline-inducible transcription system for explosive gene expression in cultured silkworm cells. Arch. Insect Biochem. Physiol. 82, 173-182. https://doi.org/10.1002/arch.21083

Ting, C.Y., Gu, S., Guttikonda, S., Lin, T.Y., White, B.H., Lee, C.H., 2011. Focusing transgene expression in Drosophila by Coupling Gal4 with a Novel Split-Lex A Expression System. Genetics 188, 229-233. https://doi.org/10.1534/genetics.110.126193

Tirian, L., Dickson, B.J., 2017. The VT GAL4, LexA, and split-GAL4 driver line collections for targeted expression in the Drosophila nervous system. Preprint on bioRxiv. https://doi.org/https://doi.org/10.1101/198648 
Trauth, J., Scheffer, J., Hasenjäger, S., Taxis, C., 2019. Synthetic Control of Protein Degradation during Cell Proliferation and Developmental Processes. ACS Omega 4, 2766-2778. https://doi.org/10.1021/acsomega.8b03011

Trost, M., Blattner, A.C., Lehner, C.F., 2016. Regulated protein depletion by the auxin-inducible degradation system in Drosophila melanogaster. Fly (Austin). 10, 35-46. https://doi.org/10.1080/19336934.2016.1168552

Urlinger, S., Baron, U., Thellmann, M., Hasan, M.T., Bujard, H., Hillen, W., 2000. Exploring the sequence space for tetracycline-dependent transcriptional activators: Novel mutations yield expanded range and sensitivity. Proc. Natl. Acad. Sci. 97, 7963-7968. https://doi.org/10.1073/pnas.130192197

Vázquez-manrique, R.P., Legg, J.C., Olofsson, B., Ly, S., Baylis, H.A., 2010. Genomics Improved gene targeting in $C$. elegans using counter-selection and Flp-mediated marker excision. Genomics 95, 37-46. https://doi.org/10.1016/j.ygeno.2009.09.001

Voutev, R., Hubbard, E.J.A., 2008. A “"FLP-Out”' System for Controlled Gene Expression in Caenorhabditis elegans. Genetics 119, 103-119. https://doi.org/10.1534/genetics.108.090274

Wang, H., Liu, J., Gharib, S., Chai, C.M., Erich, M., Pokala, N., Sternberg, P.W., 2017. cGAL, a Temperature-Robust GAL4-UAS System for C. elegans. Nat. Methods 14, 145-148. https://doi.org/10.1038/nmeth.4109.cGAL

Wang, H., Liu, J., Yuet, K.P., Hill, A.J., Sternberg, P.W., 2018. Split cGAL, an intersectional strategy using a split intein for refined spatiotemporal transgene control in Caenorhabditis elegans. PNAS 115, 3900-3905. https://doi.org/10.1073/pnas.1720063115

Wang, S., Tang, N.H., Lara-Gonzalez, P., Zhao, Z., Cheerambathur, D.K., Prevo, B., Chisholm, A.D., Desai, A., Oegema, K., 2017. A toolkit for GFP-mediated tissue-specific protein degradation in C. elegans. Development 144, 2694-2701. https://doi.org/10.1242/dev.150094

Wang, S.-R., Wu, L.-Y., Huang, H.-Y., Xiong, W., Liu, J., Wei, L., Yin, P., Tian, T., Zhou, X., 2020. Conditional control of RNA-guided nucleic acid cleavage and gene editing. Nat. Commun. 11, 91. https://doi.org/10.1038/s41467-019-13765-3

Wang, X., Chen, X., Yang, Y., 2012. Spatiotemporal control of gene expression by a light-switchable transgene system. Nat. Methods 9, 266-269. https://doi.org/10.1038/nmeth.1892

Webster, N., Jin, J.R., Green, S., Hollis, M., Chambon, P., 1988. The yeast UASG is a transcriptional enhancer in human hela cells in the presence of the GAL4 trans-activator. Cell 52, 169-178. https://doi.org/10.1016/0092-8674(88)90505-3

Wei, X., Potter, C.J., Luo, L., Shen, K., 2012. Controlling gene expression with the Q repressible binary expression system in Caenorhabditis elegans. Nat. Methods 9, 391-395. https://doi.org/10.1038/nmeth.1929

Weinberg, B.H., Cho, J.H., Agarwal, Y., Pham, N.T.H., Caraballo, L.D., Walkosz, M., Ortega, C., Trexler, M., Tague, N., Law, B., Benman, W.K.J., Letendre, J., Beal, J., Wong, W.W., 2019. High-performance chemical- and light-inducible recombinases in mammalian cells and mice. Nat. Commun. 10, 4845. https://doi.org/10.1038/s41467-019-12800-7

White, B.H., Osterwalder, T.P., Yoon, K.S., Joiner, W.J., Whim, M.D., Kaczmarek, L.K., Keshishian, H., Haven, N., 2001. Targeted Attenuation of Electrical Activity in Drosophila Using a Genetically 
Modified K+ Channel. Neuron 31, 699-711. https://doi.org/https://doi.org/10.1016/S08966273(01)00415-9

Wu, Q., Ploegh, H.L., Truttmann, M.C., 2017. Hepta-Mutant Staphylococcus aureus Sortase A (SrtA7m) as a Tool for in Vivo Protein Labeling in Caenorhabditis elegans. ACS Chem. Biol. 12, 664-673. https://doi.org/10.1021/acschembio.6b00998

Wurmthaler, L.A., Sack, M., Gense, K., Hartig, J.S., Gamerdinger, M., 2019. A tetracycline-dependent ribozyme switch allows conditional induction of gene expression in Caenorhabditis elegans. Nat. Commun. 10, 491. https://doi.org/10.1038/s41467-019-08412-w

Xu, R.-G., Wang, X., Shen, D., Sun, J., Qiao, H.-H., Wang, F., Liu, L.-P., Ni, J.-Q., 2019. Perspectives on gene expression regulation techniques in Drosophila. J. Genet. Genomics 46, 213-220. https://doi.org/10.1016/j.jgg.2019.03.006

$\mathrm{Xu}, \mathrm{T} ., \mathrm{Rubin}, \mathrm{G} . \mathrm{M.}, 1993$. Analysis of genetic mosaics in developing and adult Drosophila tissues. Development 117, 1223-1237.

Yamada, M., Suzuki, Y., Nagasaki, S.C., Okuno, H., Imayoshi, I., 2018. Light Control of the Tet Gene Expression System in Mammalian Cells. Cell Rep. 25, 487-500. https://doi.org/10.1016/j.celrep.2018.09.026

Yonemura, N., Tamura, T., Uchino, K., Kobayashi, I., Tatematsu, K., lizuka, T., Tsubota, T., Sezutsu, H., Muthulakshmi, M., Nagaraju, J., Kusakabe, T., 2013. phiC31-integrase-mediated, site-specific integration of transgenes in the silkworm, Bombyx mori (Lepidoptera: Bombycidae). Appl. Entomol. Zool. 48, 265-273. https://doi.org/10.1007/s13355-013-0182-6

Zetsche, B., Volz, S.E., Zhang, F., 2015. A split-Cas9 architecture for inducible genome editing and transcription modulation. Nat. Biotechnol. 33, 139-142. https://doi.org/10.1038/nbt.3149

Zhang, L., Ward, J.D., Cheng, Z.Z., Dernburg, A.F., 2015. The auxin-inducible degradation (AID) system enables versatile conditional protein depletion in C. elegans. Development 142, 4374-4384. https://doi.org/10.1242/dev.129635

Zhou, L., Schnitzler, A., Agapite, J., Schwartz, L.M., Steller, H., Nambu, J.R., 1997. Cooperative functions of the reaper and head involution defective genes in the programmed cell death of Drosophila central nervous system midline cells. Proc. Natl. Acad. Sci. 94, 5131-5136. https://doi.org/10.1073/pnas.94.10.5131

Zhou, Q., Neal, S.J., Pignoni, F., 2016. Mutant analysis by rescue gene excision: New tools for mosaic studies in Drosophila. Genesis 54, 589-592. https://doi.org/10.1002/dvg.22984 


\begin{tabular}{|c|c|c|c|c|}
\hline System & Stimulus & Control & Directionality & Organism \\
\hline \multicolumn{5}{|l|}{ Heat shock promoter } \\
\hline - Endogenous & Heat & Temporal & Bidirectional & $\begin{array}{l}\text { Dmel (Lis et al., 1983), Cele (Stringham et al., } \\
\text { 1992), Spur (McMahon et al., 1984), Cint } \\
\text { (Kawaguchi et al., 2015), Tcas (Silver et al., } \\
\text { 2015), Sfru (Chen et al., 2020) }\end{array}$ \\
\hline - Laser & Heat (laser) & Temporal + Spatial & ON (bidirectional) & $\begin{array}{l}\text { Dmel (Halfon et al., 1997), Cele (Stringham } \\
\text { and Candido, 1993) }\end{array}$ \\
\hline - $h s f-1$ background & Heat & Temporal + Spatial & ON (bidirectional) & Cele (Bacaj and Shaham, 2007) \\
\hline \multicolumn{5}{|l|}{ Recombinases } \\
\hline - Cre-LoxP & Heat & Temporal + Spatial & ON or OFF & $\begin{array}{l}\text { Dmel (Siegal and Hartl, 1996), Cele (Hoier et } \\
\text { al., 2000), Asus (Schetelig and Handler, 2013), } \\
\text { Bmor (Duan et al., 2013) }\end{array}$ \\
\hline - Flp-FRT & Heat & Temporal + Spatial & ON or OFF & $\begin{array}{l}\text { Dmel (Golic and Lindquist, 1989), Cele (Davis } \\
\text { et al., 2008; Voutev and Hubbard, 2008), Aaeg } \\
\text { (Morris et al., 1991), Bmor (Long et al., 2012) }\end{array}$ \\
\hline - lox-stop-lox / Flp-out & Heat & Temporal + Spatial & ON & $\begin{array}{l}\text { Dmel }{ }^{28}, \text { Cele (Davis et al., 2008; Voutev and } \\
\text { Hubbard, 2008), Bmor (Duan et al., 2013) }\end{array}$ \\
\hline - FLEX & Heat & Temporal + Spatial & ON or OFF & Dmel (Fisher et al., 2017) \\
\hline - Flp-DD & Compound (trimethoprim) & Temporal + Spatial & ON or OFF & Dmel (Sethi and Wang, 2017) \\
\hline - Cre-EBD & Compound (oestrogen) & Temporal + Spatial & ON or OFF & Dmel (Heidmann and Lehner, 2001) \\
\hline - Photoactivatable Split-Cre & Light (blue) & Temporal + Spatial & ON or OFF & Dmel (Boulina et al., 2013) \\
\hline - PhiC31 & Heat & Temporal + Spatial & ON or OFF & $\begin{array}{l}\text { Dmel (Groth, 2004), Aaeg (Nimmo et al., } \\
\text { 2006), Bmor (Yonemura et al., 2013), Agam } \\
\text { (Meredith et al., 2011), Aalb (Labbé et al., } \\
\text { 2010), Pxyl (Haghighat-Khah et al., 2015) }\end{array}$ \\
\hline$-\mathrm{KD}, \mathrm{R}, \mathrm{B} 2$ and $\mathrm{B} 3$ & Heat & Temporal + Spatial & ON or OFF & Dmel (Nern et al., 2011) \\
\hline - Laser-TAC & Light (UV) & Temporal + Spatial & ON or OFF & Cele (Davis et al., 2020) \\
\hline \multicolumn{5}{|l|}{ Tet system } \\
\hline - Tet-Off & Compound (Tet/Dox) & Temporal + Spatial & OFF (bidirectional) & $\begin{array}{l}\text { Dmel (Bello et al., 1998), Aste (Lycett et al., } \\
\text { 2004) }\end{array}$ \\
\hline - Tet-On & Compound (Tet/Dox) & Temporal + Spatial & ON (bidirectional) & $\begin{array}{l}\text { Dmel (Bieschke et al., 1998), Aste (Lycett et } \\
\text { al., 2004), Bmor (Karasaki et al., 2009) }\end{array}$ \\
\hline - rtTA-M2-alt & Compound (Tet/Dox) & Temporal + Spatial & ON (bidirectional) & Dmel (Stebbins et al., 2001) \\
\hline
\end{tabular}




\begin{tabular}{|c|c|c|c|c|}
\hline - Gal4-UAS & Heat & Temporal or Spatial & ON (bidirectional) & $\begin{array}{l}\text { Dmel (Brand and Perrimon, 1993), Cele (H. } \\
\text { Wang et al., 2017), Tcas (Schinko et al., 2010), } \\
\text { Aaeg (Kokoza and Raikhel, 2011), Agam (Lynd } \\
\text { and Lycett, 2012), Aste (Brochta et al., 2012), } \\
\text { Bmor (Imamura et al., 2003), Spur (Mao et al., } \\
\text { 1996), Lpic (Mao et al., 1996), Sint (Bulgakov } \\
\text { et al., 2002), Smir (Bulgakov et al., 2002) }\end{array}$ \\
\hline - TARGET & Heat & Temporal + Spatial & Bidirectional & Dmel (McGuire et al., 2003) \\
\hline- Gal4ts & Heat & Temporal + Spatial & Bidirectional & Dmel (Mondal et al., 2007) \\
\hline - GeneSwitch & Compound (mifepristone) & Temporal + Spatial & Bidirectional & Dmel (Osterwalder et al., 2001) \\
\hline - Gal80-DD & Compound (trimethoprim) & Temporal + Spatial & Bidirectional & Dmel (Sethi and Wang, 2017) \\
\hline - Laser & Heat (laser) & Temporal + Spatial & ON (bidirectional) & Dmel (Halfon et al., 1997) \\
\hline - Photocaged Gal4 & Light (UV) & Temporal + Spatial & ON (bidirectional) & Dmel (Cambridge, 1997) \\
\hline - Split-Gal4 & Heat & Temporal + Spatial & ON (bidirectional) & $\begin{array}{l}\text { Dmel (Luan et al., 2006), Cele (Wang et al., } \\
\text { 2018) }\end{array}$ \\
\hline - Split-Gal4-KZip ${ }^{+}$ & Heat & Temporal + Spatial & ON (bidirectional) & Dmel (Dolan et al., 2017) \\
\hline - LexA-lexO & Heat & Temporal or Spatial & ON (bidirectional) & Dmel (Lai and Lee, 2006), Cele (Nonet, 2020) \\
\hline - Gal80-repressible LexA & Heat & Temporal + Spatial & ON (bidirectional) & Dmel (Lai and Lee, 2006) \\
\hline - Split-LexA & Heat & Temporal + Spatial & ON (bidirectional) & Dmel (Ting et al., 2011) \\
\hline - Photoactivatable LexA & Light (blue) & Temporal + Spatial & ON (bidirectional) & Dmel (Chan et al., 2015) \\
\hline \multicolumn{5}{|l|}{ Q system } \\
\hline - Q system & Compound (QA) & Temporal + Spatial & ON (bidirectional) & $\begin{array}{l}\text { Dmel (Potter et al., 2010), Cele (Wei et al., } \\
\text { 2012) }\end{array}$ \\
\hline - Split-Q & Compound (QA) & Temporal + Spatial & ON (bidirectional) & $\begin{array}{l}\text { Dmel (Riabinina et al., 2019), Cele (Wei et al., } \\
\text { 2012) }\end{array}$ \\
\hline - QF2 & Compound (QA) & Temporal + Spatial & ON (bidirectional) & $\begin{array}{l}\text { Dmel (Riabinina et al., 2015), Cele (Nonet, } \\
\text { 2020), Agam (Riabinina et al., 2016), Acol } \\
\text { (Afify et al., 2019), Aaeg (Matthews et al., } \\
\text { 2019) }\end{array}$ \\
\hline$-\mathrm{QF2}^{\mathrm{w}}$ & Compound (QA) & Temporal + Spatial & ON (bidirectional) & $\begin{array}{l}\text { Dmel (Riabinina et al., 2015), Cele (Aoki et al., } \\
\text { 2018) }\end{array}$ \\
\hline - QF-GR & $\begin{array}{l}\text { Compound } \\
\text { (dexamethasone/QA) }\end{array}$ & Temporal + Spatial & ON (bidirectional) & Cele (Monsalve et al., 2019) \\
\hline
\end{tabular}




\begin{tabular}{|c|c|c|c|c|}
\hline \multicolumn{5}{|l|}{ Combinatorial } \\
\hline - Tet-Off-Gal80 & Compound (Tet/Dox) & Temporal + Spatial & ON (bidirectional) & Dmel (Barwell et al., 2017) \\
\hline - Gal4-Tet-Off & Compound (Tet/Dox) & Temporal + Spatial & ON (bidirectional) & Dmel (Stebbins and Yin, 2001) \\
\hline - Gal4-Tet-On & Compound (Tet/Dox) & Temporal + Spatial & ON (bidirectional) & Dmel (Stebbins et al., 2001) \\
\hline - Tet-Q & Compound (Tet/Dox) & Temporal + Spatial & ON (bidirectional) & Cele (Mao et al., 2019) \\
\hline - Q-Gal4 + Q-LexA & Compound (QA) & Temporal + Spatial & ON (bidirectional) & Dmel (Riabinina et al., 2015) \\
\hline - Gal4-FLP + Gal4-Cre & Heat & Temporal + Spatial & (ON or) OFF & Dmel (Frickenhaus et al., 2015) \\
\hline - Tet-On-Cre & Compound (Tet/Dox) & Temporal + Spatial & ON or OFF & Cele (Mao et al., 2019) \\
\hline \multicolumn{5}{|l|}{ Post-transcriptional } \\
\hline - Riboswitch & Compound (Tet) & Temporal & ON (bidirectional) & Cele (Wurmthaler et al., 2019) \\
\hline - RNA interference & Double-stranded RNA & Temporal + Spatial & OFF & Dmel (Xu et al., 2019), Cele (Ahringer, 2006) \\
\hline - deGradFP & GFP nanobody expression ${ }^{b}$ & Temporal + Spatial & OFF (bidirectional) & $\begin{array}{l}\text { Dmel (Caussinus et al., 2012), Cele (S. Wang et } \\
\text { al., 2017) }\end{array}$ \\
\hline - ZF1 & ZIF-1 expression ${ }^{b}$ & Temporal + Spatial & OFF (bidirectional) & Cele (Armenti et al., 2014) \\
\hline - AID & Compound (auxin) & Temporal & Bidirectional & $\begin{array}{l}\text { Dmel (Trost et al., 2016), Cele (Zhang et al., } \\
\text { 2015) }\end{array}$ \\
\hline - DiPD & Compound (rapamycin) & Temporal & Bidirectional & Cele (Deng et al., 2020) \\
\hline - DD & Compound (trimethoprim) & Temporal & Bidirectional & $\begin{array}{l}\text { Dmel (Sethi and Wang, 2017), Cele (Cho et al., } \\
\text { 2013) }\end{array}$ \\
\hline - It-degron & Heat & Temporal & Bidirectional & Dmel (Faden et al., 2016) \\
\hline$-\mathrm{SrtA}_{7 \mathrm{~m}}$ & Heat & Temporal & Bidirectional & Cele (Wu et al., 2017) \\
\hline - CALI & Light (blue) & Temporal + Spatial & Bidirectional & Cele (Lin et al., 2013) \\
\hline - psd & Light (blue) & Temporal + Spatial & OFF (bidirectional) & Cele (Hermann et al., 2015) \\
\hline - Morphotrap & GFP nanobody expression ${ }^{b}$ & Temporal + Spatial & OFF (bidirectional) & $\begin{array}{l}\text { Dmel (Harmansa et al., 2015), Cele (Pani and } \\
\text { Goldstein, 2018) }\end{array}$ \\
\hline - Photo-trapping & Light (blue) & Temporal + Spatial & Bidirectional & Cele (Fielmich et al., 2018) \\
\hline
\end{tabular}


Table 1. Overview of systems for conditional gene expression. Dmel, Drosophila melanogaster (common

1270 fruit fly); Cele, Caenorhabditis elegans (nematode); Spur, Strongylocentrotus purpuratus (purple sea

1271 urchin); Cint, Ciona intestinalis (vase tunicate); Tcas, Tribolium castaneum (red flour beetle); Sfru,

1272 Spodoptera frugiperda (fall armyworm); Asus, Anastrepha suspensa (Caribbean fruit fly); Bmor, Bombyx

1273 mori (silkworm); Aaeg, Aedes aegypti (yellow fever mosquito); Agam, Anopheles gambiae (African

1274 malaria mosquito); Aalb, Aedes albopictus (Asian tiger mosquito); Pxyl, Plutella xylostella (diamondback

1275 moth); Aste, Anopheles stephensi (Indian malaria mosquito); Lpic, Lytechinus pictus (painted urchin);

1276 Sint, Strongylocentrotus intermedius (sea urchin); Smir, Scaphechinus mirabilis (sea urchin); Acol,

1277 Anopheles coluzzii (African malaria mosquito); CALI, chromophore-assisted light inactivation; It-degron,

1278 low-temperature-controlled degron; DD, destabilizing domain; DiPD, drug-induced protein depletion;

1279 ZF1, zinc-finger domain 1; AID, auxin-inducible degradation; psd, photosensitive degron; Tet,

1280 tetracycline; Dox, doxycycline; TARGET, Temporal And Regional Gene Expression Targeting; Cre-EBD,

1281 Cre-estrogen binding domain; Laser-TAC, Laser Targeted Activation of Cre; FLEx, flip excision. Systems

1282 discussed in this review are listed alongside their (in)activation stimulus, level, and directionality of

1283 control and in which organisms they are applicable (with a reference to their first use in each organism).

1284 When parentheses are used in the directionality column, the direction mentioned is theoretically 1285 possible but has not yet been tested in vivo. ${ }^{a}$ Applied in several organisms; refer to cited reviews for 1286 more details. ${ }^{b}$ The stimulus depends on the system driving expression.

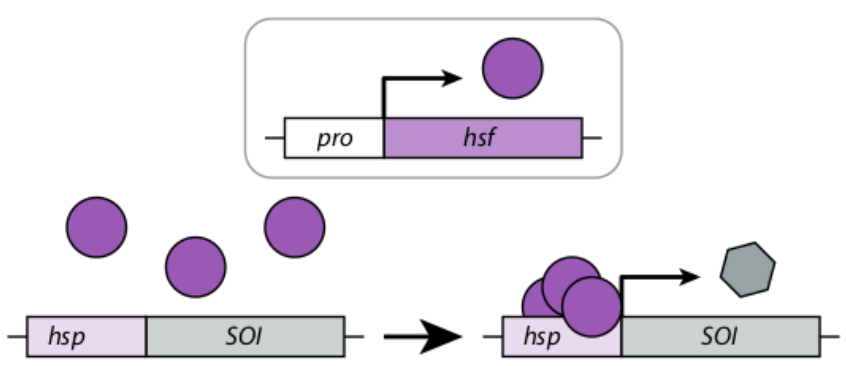

heat shock

1288 Fig. 1. Conditional expression using heat shock promoters. The heat shock factor gene ( $h s f$ is 1289 constitutively expressed under its endogenous promoter (pro) and is thus present in its inactive, 1290 monomeric form throughout the organism. A sequence of interest (SOI) under the control of a heat 1291 shock responsive promoter ( $h s p)$ is transgenically introduced. Upon heat shock, heat shock factor (HSF) 1292 trimerizes, allowing it to bind $h s p$ and drive expression of the SOI. Alternatively, $h s f$ can be rescued 1293 under the control of a tissue-specific promoter in an $h s f$ knockout background, adding spatial control. 

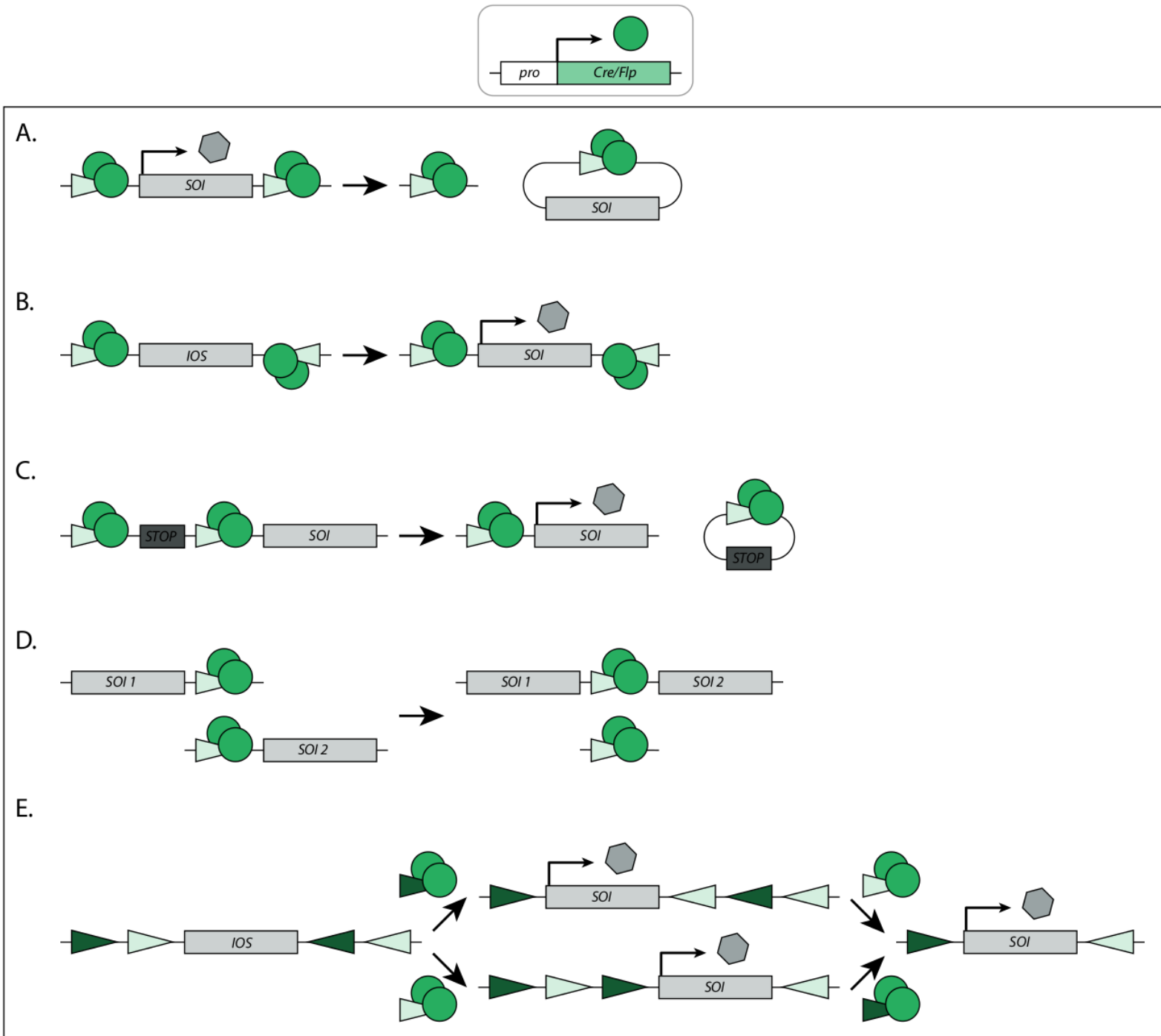

F.
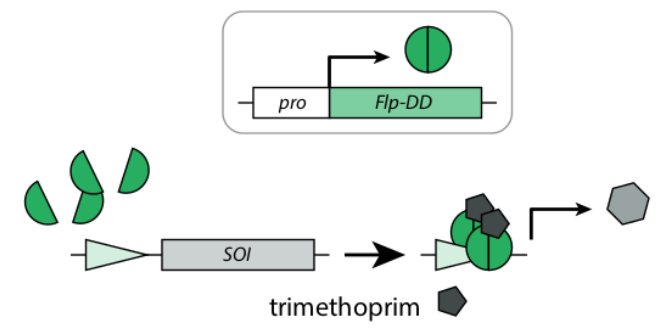

H.
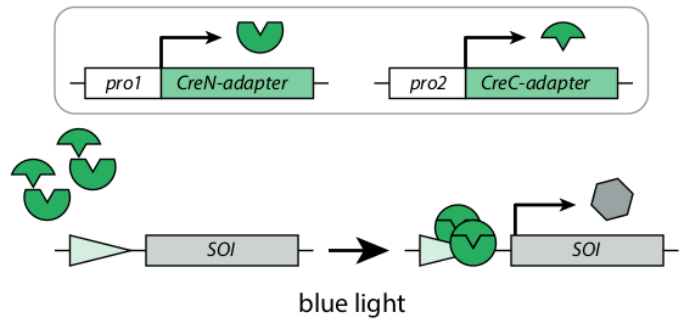

G.
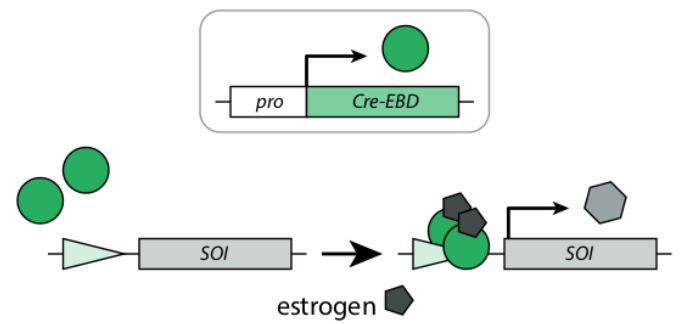

I.
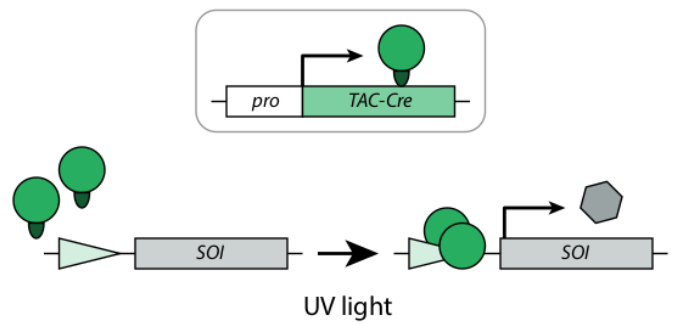
1295 Fig. 2. Recombinase-based conditional expression relying on Cre-LoxP or Flp-FRT. Cre or Flp recombinase

1296 are transgenically expressed under the control of a heat shock or tissue-specific promoter (pro). LoxP or

1297 FRT sites are present flanking a sequence of interest (SOI). Depending on their orientation, the

1298 recombinase will (A) excise or (B) invert the SOI, which can lead to gene (in)activation. (C) Alternatively,

1299 in the lox-stop-lox or Flp-out systems, a stop cassette preventing transcription is present upstream of

1300 the SOI, flanked by loxP or FRT sites. Upon recombinase expression, the stop cassette is excised,

1301 allowing transcription of the SOI. (D) When loxP or FRT sites are integrated on different chromosome

1302 arms, trans-chromosomal recombination can be used to create mosaic animals. (E) A flip excision (FLEx)

1303 switch avoids a SOI inverting back to its original orientation, by relying on two pairs of different

1304 recognition sites. After inversion, one of these sites is excised, preventing further inversions. (F) A

1305 destabilized Flp (Flp-DD) is only stable - thus, able to drive recombination-upon addition of

1306 trimethoprim. (G) A compound-regulated Cre-estrogen binding domain (Cre-EBD) can only bind and

1307 drive recombination upon addition of estrogen. (H) Split-Cre dimerizes to drive recombination upon

1308 illumination with blue light. (I) Photocaged Cre (TAC-Cre) is uncaged and able to drive recombination

1309 upon illumination with UV light. 
A.
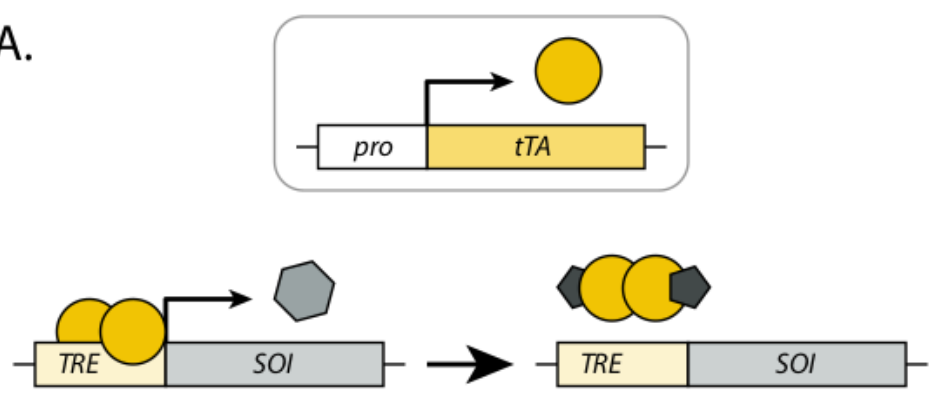

doxycycline

B.
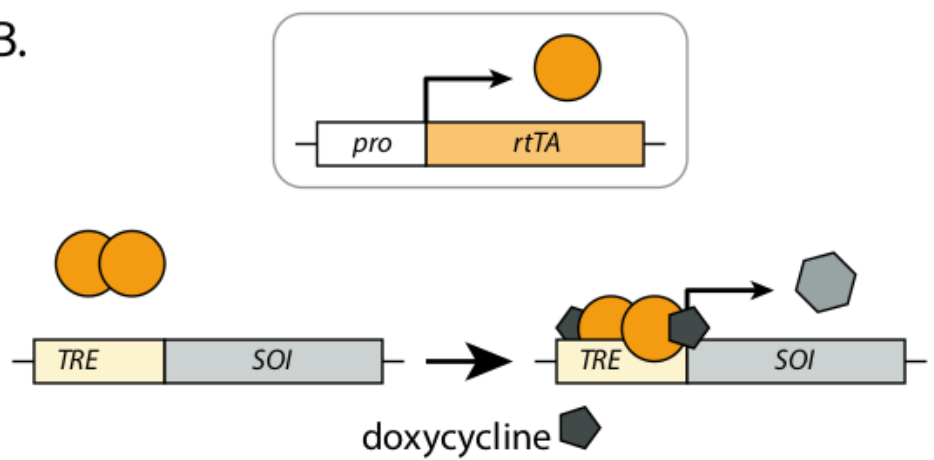

1310

1311 Fig. 3. Tetracycline-dependent conditional expression. (A) In the Tet-Off system, tetracycline

1312 transactivator $(t T A)$ is transgenically expressed under the control of a tissue-specific promoter (pro). tTA

1313 dimers can bind and activate a tetracycline response element (TRE) upstream of a sequence of interest

$1314(\mathrm{SOI})$, allowing transcription. Addition of tetracycline or doxycycline inactivates tTA, preventing

1315 transcription. (B) In the Tet-On system, reverse tetracycline transactivator (rtTA) is transgenically

1316 expressed under a tissue-specific promoter. rtTA dimers can only bind and activate TRE and the SOI in

1317 the presence of tetracycline or doxycycline. 
A.
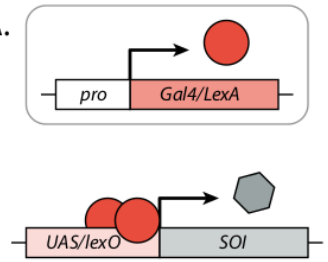

B.
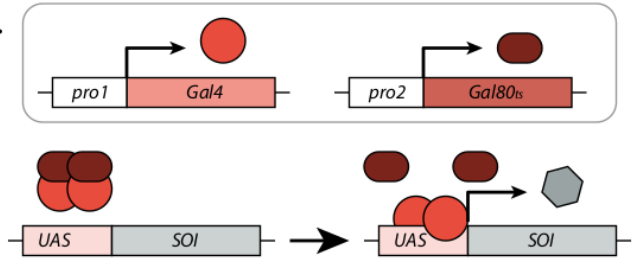

heat shock

c.
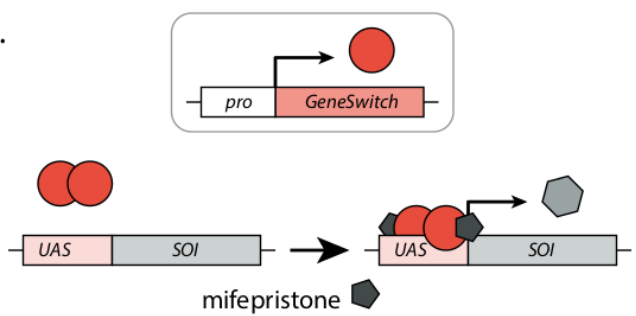

D.

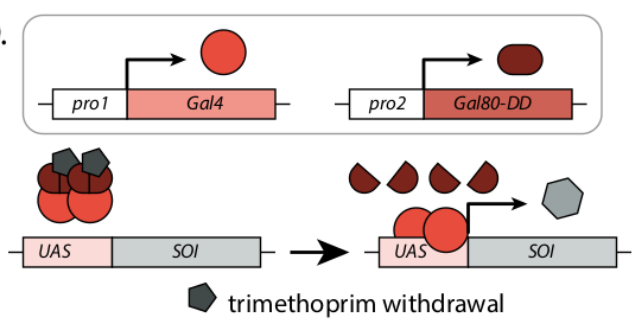

E.
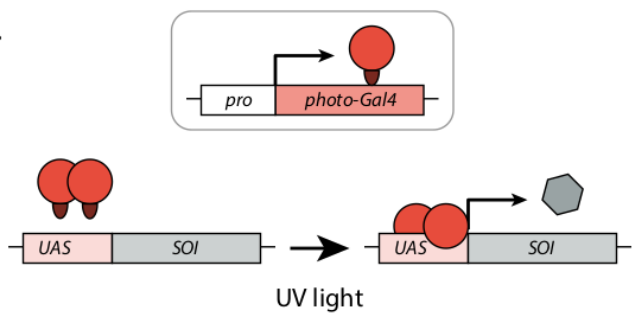

F.
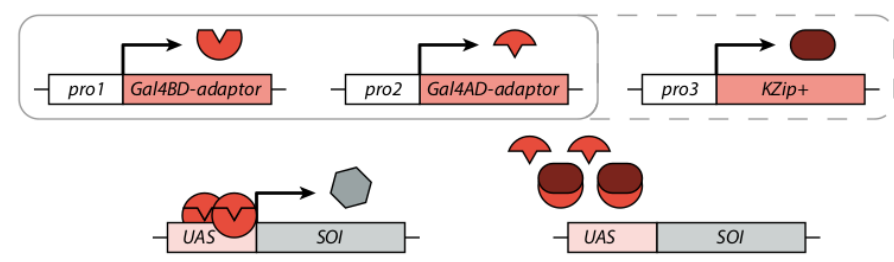

G.

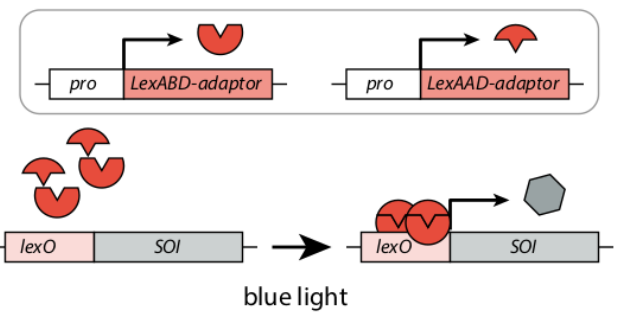


1319 Fig. 4. The binary Gal4-UAS system as used for conditional gene expression. (A) Transcriptional activator 1320 Gal4 or LexA is transgenically expressed under the control of a heat shock or tissue-specific promoter 1321 (pro). It can bind an upstream activation sequence (UAS) or LexA operator (lexO), driving expression of a 1322 downstream sequence of interest (SOI). A temperature-sensitive version of Gal4 can also be used, which 1323 is inactivated at higher temperatures. (B) Gal80, a repressor of Gal4, can be expressed under a second 1324 tissue-specific promoter. In Temporal And Regional Gene Expression Targeting (TARGET), temperature1325 sensitive Gal80ts is used, and heat shock can inactivate the repressor, allowing binding of Gal4 to the 1326 UAS and activation of transcription. (C) In the GeneSwitch system, a modified form of Gal4 is used, 1327 which is sensitive to the steroid mifepristone. GeneSwitch can only bind UAS and activate transcription 1328 upon addition of mifepristone. (D) A destabilized Gal80 (Gal80-DD) is stable while in the presence of 1329 trimethoprim and thus blocks activation by Gal4, but destabilizes upon addition of trimethoprim, thus 1330 allowing expression. (E) A photocaged Gal4 can be used that is uncaged (and thus able to bind UAS and 1331 activate expression) upon illumination with UV light. (F) In Split-Gal4, the activation domain (AD) and 1332 binding domain (BD) are each expressed under a different promoter, fused to an adaptor. Only where 1333 expression overlaps will the two domains combine via the adaptor and activate expression. In addition, 1334 when expressing the Killer Zipper (KZip+) from a third promoter, the formation of split-Gal4 dimers will 1335 be disrupted in a subset of cells, preventing Gal4 activity there. (G) In the photoactivatable split-LexA 1336 system, the VP16 AD and LexA BD are each fused to an adaptor, which dimerizes upon illumination with 1337 blue light, enabling transcription of a SOI upstream of a lexO site. 
A.
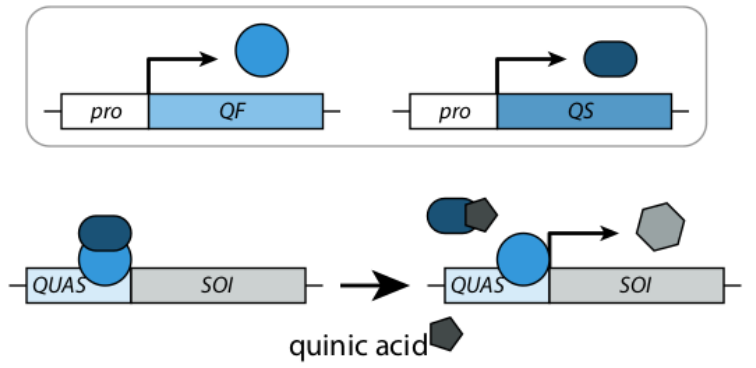

B.
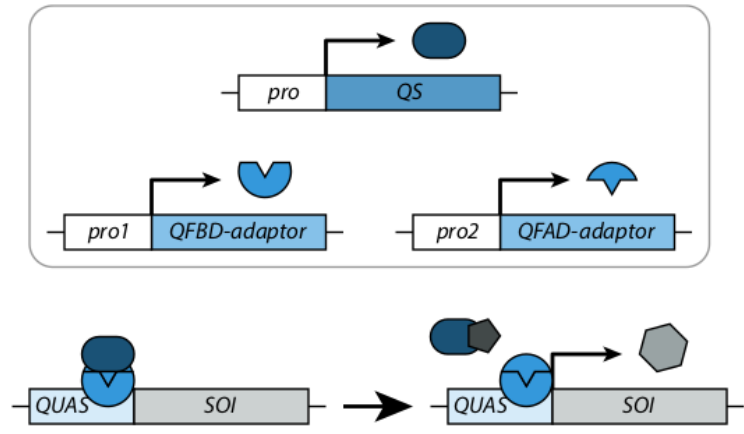

quinic acid

C.
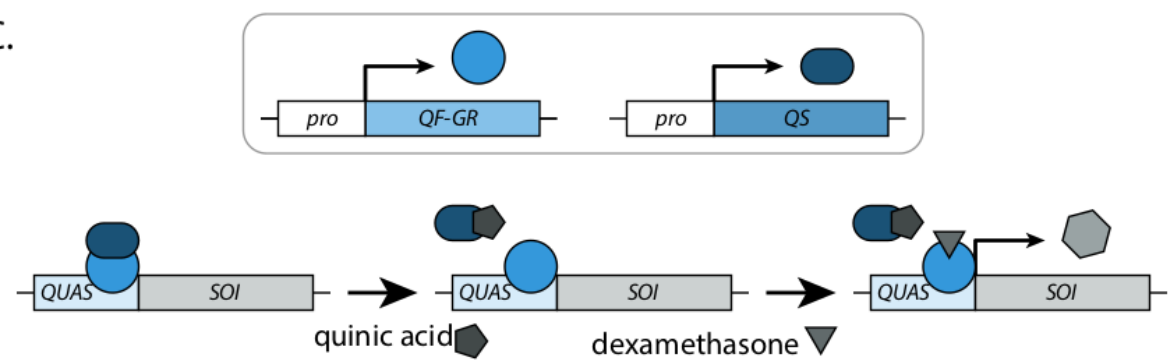

1339 Fig. 5. Reversible control over gene expression by means of the Q system. (A) Transcriptional activator

1340 QF and its repressor QS are transgenically expressed under the control of a tissue-specific promoter

1341 (pro). QS binds and suppresses the activity of QF. Upon addition of quinic acid (QA), QS is sequestered

1342 and QF can bind to the QUAS enhancer sequence that is followed by a basal promoter, driving

1343 expression of a downstream sequence of interest (SOI). (B) In Split-Q, the activation domain (AD) and

1344 binding domain (BD) of QF are each expressed under a different promoter, fused to an adaptor. Only

1345 where expression overlaps will the two domains combine via the adaptor and activate expression (in the

1346 presence of QA). (C) QF can be fused to a glucocorticoid receptor ligand-BD (QF-GR) so that it is only

1347 active in the presence of dexamethasone. This can be combined with QS to avoid uninduced activation of QF-GR or for more spatial refinement. 
A.
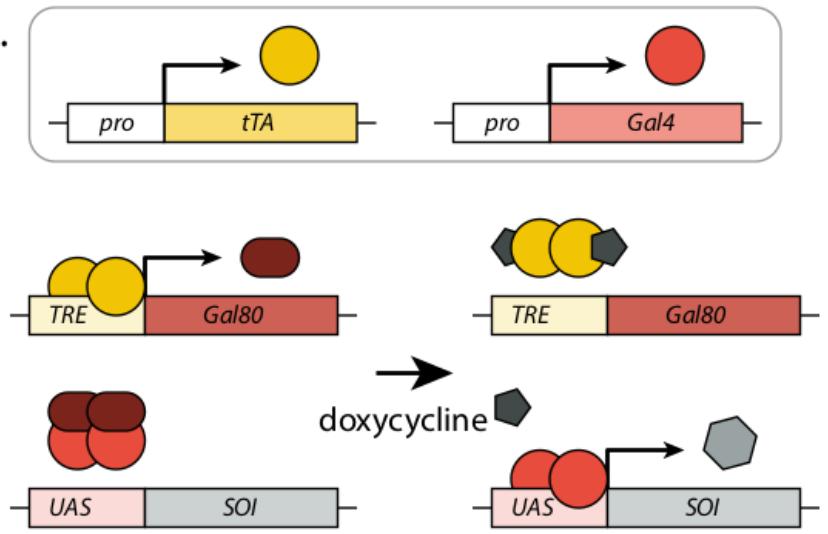

B.

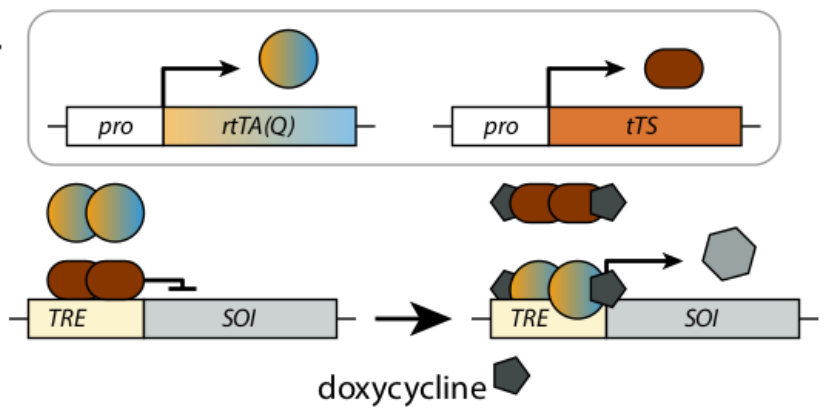

C.
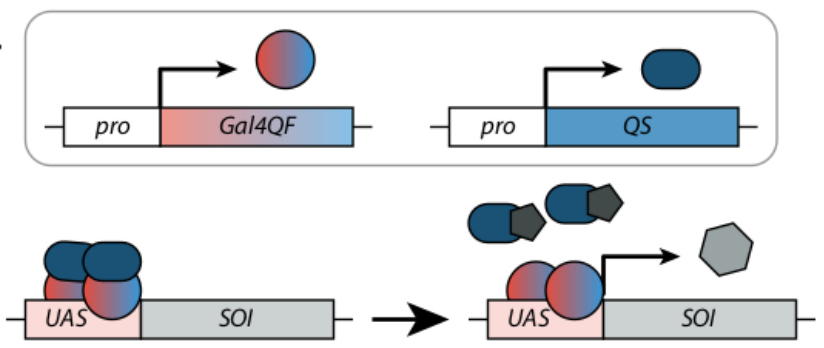

quinic acid

D.
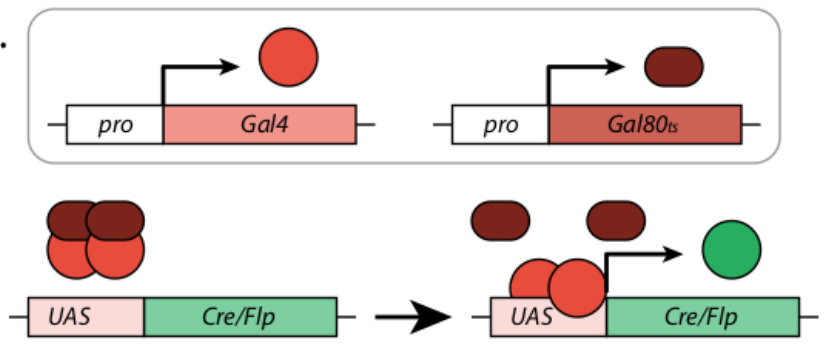

heat shock
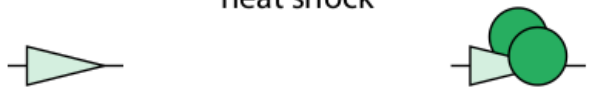
1350 Fig. 6. Combinatorial approaches integrate components of different systems for conditional gene

1351 expression. (A) In the Tet/Gal4 system, both the tetracycline transactivator (tTA) and Gal4 are

1352 transgenically expressed under the control of a tissue-specific promoter (pro). tTA dimers can bind and

1353 activate a tetracycline response element (TRE) upstream of Gal80, which is then expressed and will bind

1354 and repress Gal4. Upon addition of tetracycline or doxycycline, tTA is repressed and Gal80 transcription

1355 is halted. This allows Gal4 dimers to bind the upstream activation sequence (UAS), driving expression of

1356 a downstream sequence of interest (SOI). (B) In the Tet/Q system, a fusion of the reverse tetracycline

1357 transactivator ( $r \mathrm{tTA})$ and the QF activation domain $(\mathrm{rtTA}(\mathrm{Q}))$ is transgenically expressed under the

1358 control of a tissue-specific promoter (pro), as is a tetracycline-regulated transcriptional silencer (tTS).

$1359 \mathrm{rtTA}(\mathrm{Q})$ is inactive, while TS binds TRE and inhibits expression of a downstream SOI. Addition of

1360 tetracycline 68 or doxycycline inactivates the tTS and activates rtTA(Q), which will bind TRE and activate

1361 expression of the downstream SOI. (C) In the Gal4/Q system, a fusion of the Gal4 binding domain and

1362 the QF activation domain (Gal4QF) is transgenically expressed under the control of a tissue-specific

1363 promoter (pro), as is its repressor QS. Gal4QF activity is repressed by QS until addition of QA, upon

1364 which Gal4QF dimers can bind UAS, driving expression of a downstream SOI. (D) In the Gal4/Cre and

1365 Gal4/Flp systems, Gal4 is transgenically expressed under the control of a tissue-specific promoter (pro),

1366 as is its repressor Gal80ts. Gal4 activity is repressed by Gal80ts until heat shock, upon which Gal4 dimers

1367 can bind UAS, driving expression of downstream Cre or Flp recombinase. This in turn will allow for

1368 recombination and (in)activation of a loxP- or FRT-flanked SOI. 